\title{
Design of a route-planner for urban public transport, promoting social inclusion
}

Rafael Marques Dias

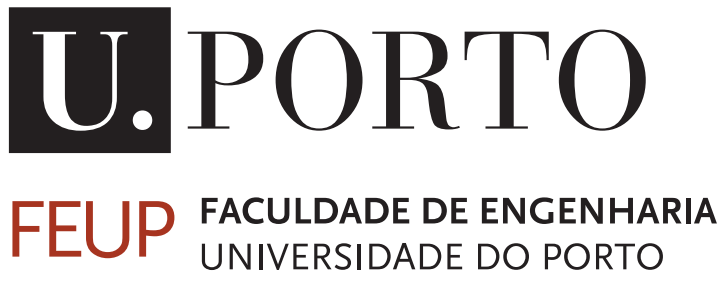

Mestrado Integrado em Engenharia Eletrotécnica e Computadores

Advisor: Tânia Fontes (Prof.)

Co-advisor: Teresa Galvão (Prof.) 
(C) Rafael Marques Dias, 2019 
Design of a route-planner for urban public transport, promoting social inclusion

\author{
Rafael Marques Dias
}

Mestrado Integrado em Engenharia Eletrotécnica e Computadores 



\section{Abstract}

In information processing by communication and information systems, some information is cast aside and considered irrelevant. However, some groups of people that suffer from various limitations such as physical, sensory and cognitive impairment need specific information (that can be considered irrelevant) for their daily life, namely their mobility. Therefore, the primary objective of this project is to design a framework and a user-interface of an inclusive inter-modal route planning application for public transportation. This was accomplished with the development of user-interfaces of an inclusive inter-modal route planning mobile application and a definition of a set of guidelines. These interfaces will deliver ready availability of information about infrastructures and other journey related data.

With the finality of achieving the objectives proposed, a three-step methodology was followed: (i) Requirements elicitation; (ii) Interfaces development; (iii) and usability evaluation. The first phase consisted in to identify the social excluded groups and understanding their limitations and current needs, particularly, what information is lacking in route planners. Based on a literature review and the results of interviews and an inquiry, a set of requirements for design the userinterfaces were proposed and assembled. For this purpose, the elderly and the mobility reduced people were chosen as focus groups. The second phase consisted in developing the mock-ups. By trying to extract information and design ideas from current route-planners and then syncing them with the requirements once reached, the interfaces were developed. The third phase consisted in evaluation of the usability of the mock-ups. This was accomplished by conducting an evaluation of the interfaces by promoting another inquiry to the population and a 1 hour session with experts in application development for public transports. In this process, the difficulty in perceiving the information was evaluated.

The overall results demonstrate that the information provided to the users, especially to mobility reduce ones, was well handled and extremely accurate. Most people considered the design appealing and intuitive. Based on the findings, the study provides guidelines for software developers and policy makers. 


\section{Resumo}

Alguma da informação que provém de sistemas de comunicação e informação é, por vezes, colocada de parte e considerada irrelevante. No entanto, alguns grupos de pessoas que sofrem de várias limitações como deficiências físicas, sensoriais e cognitivas, necessitam de informações específicas (que podem ser consideradas irrelevantes) para a sua vida diária, nomeadamente para a sua mobilidade. Assim, o objetivo principal deste projeto foi criar uma estrutura de uma interface de uma aplicação de planeamento de rotas intermodais e inclusivo para os grupos de pessoas supraditos, utilizadores de transportes públicos. Tal objetivo foi alcançado com o desenvolvimento de interfaces mock-up de uma aplicação móvel de criação de rota intermodal em concomitância com a definição de um conjunto de directrizes. Estas interfaces visam fornecer informação sobre as infraestruturas e outros dados relacionados com viagens.

Com o intuito de atingir os objetivos que foram propostos, foi implementada uma metodologia que consiste em três fases: (i) definição de requisitos; (ii) desenvolvimento das interfaces; (iii) validação. A primeira fase consistiu em identificar os grupos socialmente excluídos e entender suas limitações e necessidades atuais, no sentido de perceber quais as informações ausentes nos planeadores de rotas. Com base numa revisão de literatura e nos resultados de entrevistas e de um inquérito, foi proposto um conjunto de requisitos para o projeto de interfaces de utilizador. Os idosos e as pessoas de mobilidade reduzida foram escolhidos como o grupo de estudo deste projeto. A segunda fase consistiu no desenvolvimento dos mock-ups. Esse desenvolvimento foi realizado com base nos requisitos definidos e num estudo comparativo de outros planeadores de rota. A terceira fase consistiu na avaliação da usabilidade dos mock-ups. Para isso, foi efetuado um novo inquérito à população e marcada uma sessão com especialistas em desenvolvimento de aplicações móveis para transportes públicos. Em ambos os processos, foi avaliada a dificuldade em perceber as informações dos mock-ups.

Os resultados obtidos demonstraram que a informação integrada nas interfaces é precisa e estava bem tratada, especialmente tendo em conta pessoas com mobilidade reduzida. A grande maioria das pessoas considerou o design apelativo e intuitivo. Com base em estudos, este trabalho dita algumas guidelines para programadores de software. 


\section{Acknowledgements}

This work is the final step of my academic career, and I would not have done it alone, therefore I would like to mention some people whom I am eternally grateful.

I'll start by stating that my parents are most likely the best parents on the face of the earth. They supported me immensely throughout this tough process called university. Without their emotional and economic support I would not be able to accomplish any of this, and I will admit, they trusted me more than I trusted myself. So thank you dad, for your chill attitude and good mentoring, and thank you mom, for being extremely kind and always looking out for me. I hope I can be as great as both of you at parenting one day.

I'm very glad that my grandpa and grandma are able to see me finish this major, things have been quite rough for their end and I only wish them the best, they have been very supportive and kind to me, thank you so much, you will never be forgotten.

To every friend and colleague that I had the pleasure of meeting in this journey, I thank you, without your support I would have been lonely and uninspired to pursue this major. A humongous brofist and special thanks to João "Jals" Silva, Tiago "Twix" Fernandes, Miguel "Churi" Santos and Ricardo "anagke" Puga for being the best buddies I've ever met, you guys rock and it feels amazing to laugh with you, I hope we can continue to be friends for the rest of our lives.

I met this incredible girl two years ago and I've had the privilege of having her by my side, she supported me in every aspect of my life since then, and I cannot thank her enough for it. I hope I can repay the immense support you gave me when you reach the last year of your major. Until then I will be here for whatever you need, miss Luísa Faria. I love you.

A huge thank you to my supervisor, Eng. Tânia Fontes, for entrusting me this project and guiding me in the process. I am glad you approved the work that has been developed and I hope I met all expectations. The idea you came up with is great and will surely have some impact in future development of route planners.

To my co-supervisor Teresa Galvão and OPT, thank you very much for the opportunity of talking to you guys and receiving important feedback, I hope we can discuss some more about the work that has been done.

Finally, I would like to thank Associação Salvador for spreading my survey with their contacts and the people who participated in the interviews.

This work is partially financed by the ERDF - European Regional Development Fund through the Operational Programme for Competitiveness and Internationalisation - COMPETE 2020 Programme and by National Funds through the Portuguese funding agency, FCT - Fundacão para a Ciência e Tecnologia within project POCI-010145-FEDER-032053. 


\section{Contents}

1 Introduction 1

1.1 Framework ......................... 1

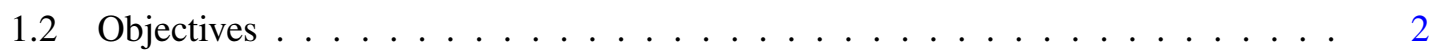

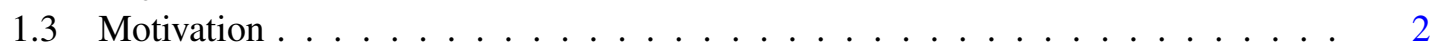

2 Literature review 3

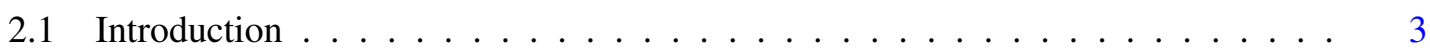

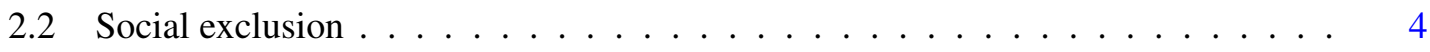

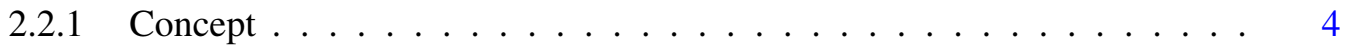

2.2.2 Mobility and transport related social exclusion . . . . . . . . . 5

2.2.3 Identification of socially excluded individuals . . . . . . . . . . . 7

2.3 Route planners . . . . . . . . . . . . . . . . . . . . . . . 10

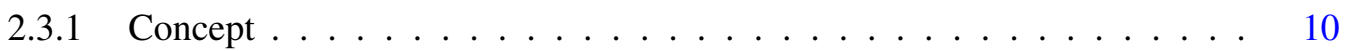

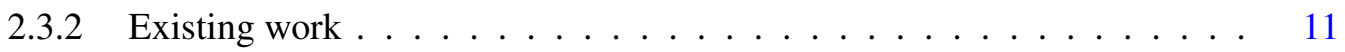

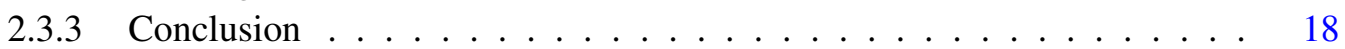

3 Problem characterization and approach $\quad 19$

3.1 Introduction . . . . . . . . . . . . . . . . . . . . . . . . 19

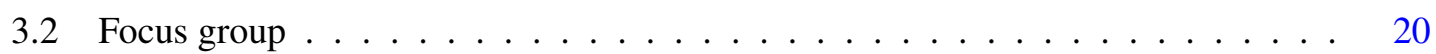

3.3 Public transport information . . . . . . . . . . . . . . . . . . . 21

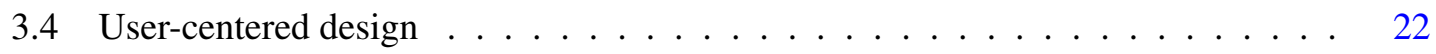

3.5 Usability . . . . . . . . . . . . . . . . . . . . . . 24

4 Requirements elicitation $\quad 27$

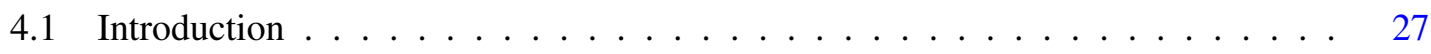

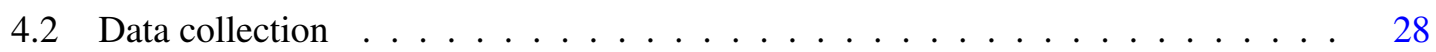

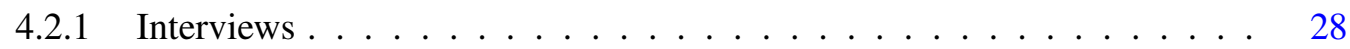

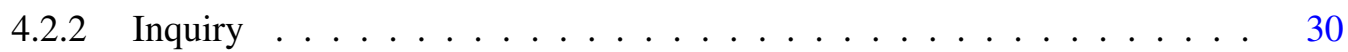

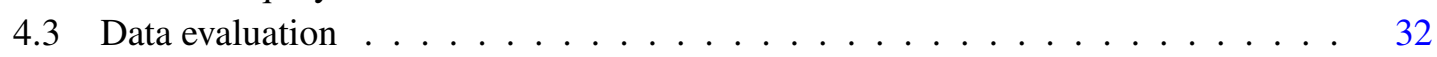

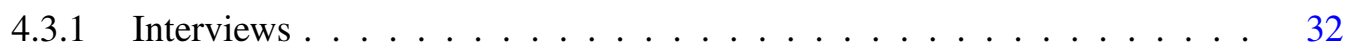

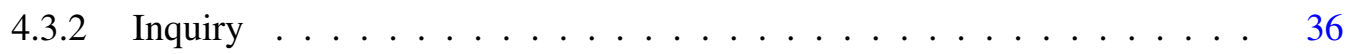

5 Interfaces development $\quad 41$

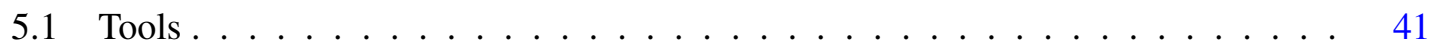

5.2 Interfaces elements and concepts . . . . . . . . . . . . . . . 41

5.2 .1 Elements . . . . . . . . . . . . . . . . . 42

5.2 .2 Concepts ......................... 43 
6 Usability evaluation $\quad 57$

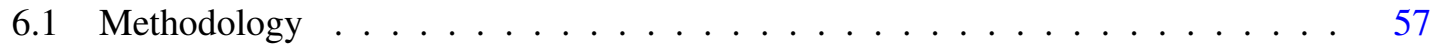

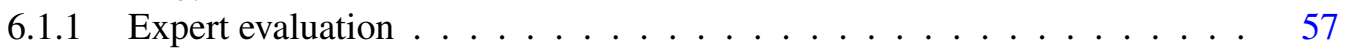

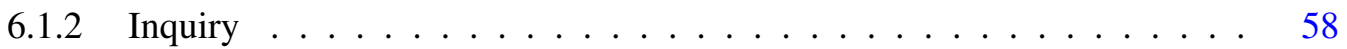

6.2 Results .......................... 58

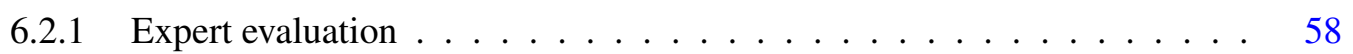

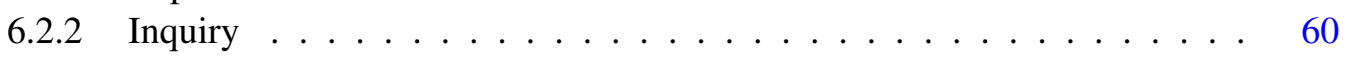

7 Conclusions and future work $\quad 63$

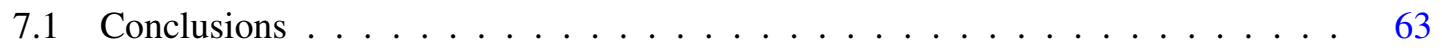

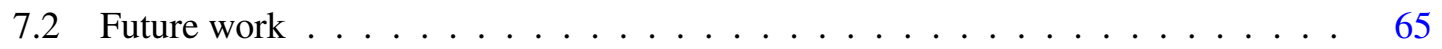

$\begin{array}{lr}\text { References } & 67\end{array}$ 


\section{List of Figures}

2.1 Differentiation of transport disadvantage, social disadvantage and social exclusion. 7

2.2 Google Maps Interfaces $($ Part 1) _ . . . . . . . . . . . . . . . . . . . . 13

2.3 Google Maps Interfaces $($ Part 2) $\ldots \ldots \ldots \ldots$

2.4 Citymapper Interfaces $($ Part 1$) \ldots \ldots \ldots \ldots$

2.5 Citymapper Interfaces $($ Part 2$) \ldots \ldots \ldots \ldots$

2.6 MOVE-ME Interfaces $($ Part 1$) \ldots \ldots \ldots \ldots \ldots \ldots$

2.7 MOVE-ME Interfaces $($ Part 2$) \ldots \ldots \ldots \ldots \ldots \ldots$

3.1 ISO 13407 interactive design process. . . . . . . . . . . . . . . 23

4.1 Porto.Bus interface when seeing the ETA of buses in a bus stop. . . . . . . . . 36

4.2 Age ranges of inquiry participants . . . . . . . . . . . . 37

4.3 Number of people with and without deficiencies who answered the inquiry . . . . 37

4.4 How people gather information about the schedules . . . . . . . . . . . . . 38

4.5 Differences of importance between information according to the users . . . . . . 39

5.1 Main page interface . . . . . . . . . . . . . . . . . . 43

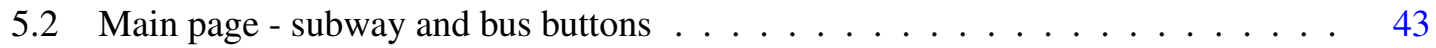

5.3 Main page - route planning button . . . . . . . . . . . . . . 44

5.4 Main page - menu button . . . . . . . . . . . . . . . . . . . 44

5.5 Subway lines interfaces $(\operatorname{Part} 1) \quad \ldots \ldots \ldots \ldots$. . . . . . . . . . . . 45

5.6 Subway lines interfaces $($ Part 2$) \ldots \ldots \ldots \ldots$. . . . . . . . . . . 46

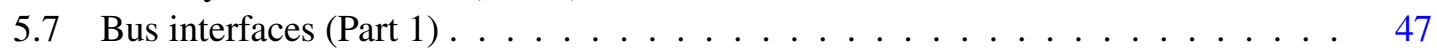

5.8 Bus interfaces $(\operatorname{Part} 2) \ldots \ldots \ldots \ldots \ldots$

5.9 Bus interfaces $(\operatorname{Part} 3) \ldots \ldots \ldots \ldots$

5.10 Route planner interfaces $($ Part 1$) \ldots \ldots \ldots \ldots \ldots \ldots$

5.11 Route planner interfaces $($ Part 2$) \ldots \ldots \ldots \ldots \ldots$. . . . . . . . . . . . 52

5.12 Route planner interfaces $($ Part 3$) \ldots \ldots \ldots \ldots$. . . . . . . . . . . 53

5.13 Menu and notifications interfaces $($ Part 1) . . . . . . . . . . . . . 54

5.14 Menu and notifications interfaces $($ Part 2) . . . . . . . . . . . 55

6.1 Likert scale used . . . . . . . . . . . . . . . . . . . . 58

6.2 Age ranges of people who participated in the inquiry for the usability evaluation . 61 


\section{List of Tables}

2.1 Groups at most risk of poverty in different countries. Source: (European Comission, 2010) adapted . . . . . . . . . . . . . . . . .

2.2 Ranking table of various trip planning applications (Source: Manchester School of Architecture (2016)) . . . . . . . . . . . . . . . . . 12

4.1 Inquiry developed . . . . . . . . . . . . . . . . . . . 31

4.2 Interview summary of the first five interviewees $\ldots \ldots \ldots . \ldots \ldots$

4.3 Interview summary of the last five interviewees $\ldots \ldots \ldots . \ldots . \ldots 34$

5.1 Main elements terminology . . . . . . . . . . . . . . . . . . . . 42

6.1 Interface average scores obtained from the usability inquiry. . . . . . . . . 61 



\section{Chapter 1}

\section{Introduction}

\subsection{Framework}

In $2016,23.5 \%$ of the European population was at risk of poverty of social exclusion, which means that 118 million people were living in either severe material deprivation, monetary poverty or were living in a household with very low work intensity. In 2017, this number lowered to $22.4 \%$, however, the percentage of the population at risk of poverty or social exclusion in three EU Member states was more than a third: Romania (35.7\%), Bulgaria (38.9\%) and Greece (34.8\%). Despite these numbers, some countries managed to grow and strengthen their economy; between 2016 and 2017, Romania, Cyprus, Poland, Slovakia and Portugal suffered a substantial decrease in the risk of poverty or social exclusion percentage, marking $35.7 \%, 25.2 \%, 19.5 \%, 16.3 \%$ and $23.3 \%$ respectively (EUROSTAT, 2017).

Social inclusion is perhaps best explained in terms of its opposite - social exclusion. The term social exclusion was initially introduced in the European policy domain during the 1990s (Shortall, 2008) and it was perceived as some sort of happening that stroke the poor exclusively. Moreover, in the literature, the terms poverty, deprivation and social exclusion have often been used interchangeably. The term social exclusion has been exhaustively discussed throughout these last decades, and, in its essence, it can be understood as the process whereby and individual becomes deprived, and not the actual deprivation itself, and in fact, poverty and deprivation can be argued as the outcomes of that process (Kamruzzaman et al., 2016). This means that the socially excluded are the ones who are not only poor, but also those who lost their ability to get a job or proceed education. The exclusion process covers various circumstances where individuals or groups of people are unable to participate in activities or to access certain goods (e.g. services, work, school, etc.) that are available to others as a fundamental part of belonging to society (Mackett and Thoreau, 2015).

Public transports play a big role in today's modern and non-modern society, specially because it facilitates the access to the goods that were referred previously; therefore, transport-related social exclusion is part of our reality, since individuals that do not have access to the transport system can be regarded as excluded. 


\subsection{Objectives}

The primary objective of this project is to design a framework of a user-interface of an inclusive inter-modal route planning application. The main questions of this research are:

(i) What are the main current social excluded groups and why?

(ii) Which necessities and limitations do those groups have?

(iii) What kind of information regarding mobility do they need the most?

(iv) In what way should that information be organized and delivered?

To develop this work, firstly, a literature review was conducted in order to identify the main social excluded groups (e.g. blind, pregnant women) and its growth trends in the next few decades. Afterwards, the main limitations and needs of the citizens involved in those groups were investigated (e.g. elevators, low passenger routes). Lastly, the framework and the user-interface was created considering those same limitations and needs, utilizing an iterative method and the participation of users. The project involved the development of a structured, comprehensive report, with the requirements specification of services the system is expected to provide as well as the specification of the guidelines that these process must be followed.

\subsection{Motivation}

There are various transport-related social exclusion parameters such as income, disability, age, gender, ethnicity, availability of transport, physical barriers, facilities, and information (Mackett and Thoreau, 2015). This last parameter is extremely important and will be one of the main focuses for this project. Information is sometimes inadequately and differently perceived by citizens, according to their socio-economic context and experience. This should have a strong impact on software applications that support choices in urban mobility. Generally, these applications adopt a standard approach, marginalizing, therefore, some population groups (e.g. the disabled, the elderly, children, pregnant women, people in poverty). In urban transport applications, this aspect is rather critical, as it can be quite important in ensuring that individuals and the different social groups can properly access work, schools, health care, services, social networks, etc, and consequently, promoting social inclusion. 


\section{Chapter 2}

\section{Literature review}

The first section of this chapter will cover the research regarding the state of the art of the social exclusion concept, social exclusion in public transports and an identification of socially excluded groups. The second section will be focused on studying the concept of route planners and the current work that has been developed in that area.

\subsection{Introduction}

The terms poverty, deprivation, and social exclusion have been used interchangeably in the literature (Kamruzzaman et al., 2016). Bearing this in mind, it is plausible to say that social exclusion is often misunderstood, poorly defined and poorly measured construct. In order to solve this issue, Kamruzzaman et al. (2016) explains that there is a need to properly identify the disadvantaged groups, or else the needs of these groups will remain unknown and the measures to prevent social exclusion from happening will not succeed.

Transport-related social exclusion has been a topic mentioned throughout the evolution of the term social exclusion itself. The key that mobility plays in social inclusion/exclusion is widely known (Lodovici and Torchio, 2015). Transports act as a middle link between the people and the opportunities that arise; therefore, it is well documented and accepted that transports have an extremely important role promoting social exclusion as well as inclusion.

Mackett and Thoreau (2015) reaffirm this idea by stating that an individual with access to the transport system may participate in many aspects of society. Lucas (2012) assert that transport and mobility inequality has been a topic mentioned in the transportation literature and that it has an important role determining social social outcomes in society.

There are different socio-economic groups that, nowadays, live in poverty and, consequently, suffer from social exclusion and transport disadvantage. In Europe, the percentages of each group differ but are quite alarming. For instance, the unemployed have a risk of poverty of $56 \%$, the elderly have it at $42 \%$, people with low training and education at $30 \%$, disabled and long-term ill people at $30 \%$, people in precarious work also at $30 \%$, people suffering from addictions at $26 \%$, 
young adults, single parents and children at 23\%, 22\% and 20\% respectively, and the list goes on (Lodovici and Torchio, 2015).

An increase in population density creates an expansion in demands on urban infrastructures, including public transports. As a consequence to this growth, comes a need for cleaner, less congested cities and improved traffic flow, specially through the increase use of enhanced public mass systems and other alternatives to private vehicles (Houghton et al., 2009). This means that reducing the demand for private transports in urban zones is a key sustainability aim (Redman et al., 2013). A viable and sustainable alternative to private vehicles would be public transports (Holmgren, 2007).

Journey planning is a vital process in public transports management. Travellers gain important information regarding the trip they wish to take by using journey/route planning apps although most of the algorithms underlying in these kinds of apps are deterministic, which means they do not cover in case of delay (i.e. traffic, red lights, etc.) (Bérczi et al., 2018). Decisions on the mode of transportation and potential routes to get to the destination are both cardinal aspects associated with journey planning. The most important factors to take into consideration in choosing routes are usually journey time and cost (Manchester School of Architecture, 2016).

\subsection{Social exclusion}

\subsubsection{Concept}

Initially introduced in the French literature, social exclusion is a term that was coined by Lenoir (1974) and it has had various definitions over the history; its concept has been changing during the years (Schwanen et al., 2015) .

It is critical to establish a substantial difference between social exclusion, poverty (Kenyon et al., 2002) and deprivation. Kamruzzaman et al. (2016) clarify that poverty is generally understood as the lack of material resources such as income, and that people may be socially excluded without being poor. Deprivation, however, is a more diffuse concept that is related to the quality of life, and to the with lack of particular attributes, as the income, which contributes to some degree of suffering or relative disadvantage. Also, European Comission (2010) state that social exclusion is another potential consequence of poverty. Kamruzzaman et al. (2016) explain that social exclusion is not only a process but also an outcome and that deprivation and poverty are outcomes of that same process; this means that there is a clear connection between those three concepts.

It is crucial to comprehend that an excluded person can have good income, which means that the poor are not the only suffering from said exclusion. Education, health care, ability to get a job are all essential rights that an excluded individual may not have access to. Schwanen et al. (2015) define the concept of social exclusion as polysemic and contested because of the diverse philosophical origins; what this means is that it has different meanings for different people and in different situations. Despite that, Schwanen et al. (2015) state that social exclusion inclines to be understood as various factors, ranging from a lack of participation in social, economic and political 
life to a multidimensional and cumulative subject that tends to aggravate (low financial resources is mutually tied to lesser education skills, which will have a negative impact in the future). Mackett and Thoreau (2015) denote that the term social exclusion is directly related with participation in activities or the access of certain goods, services and opportunities that are vital for anyone that belongs in society. In correlation with what Mackett said, Burchardt et al. (1999) also stated that:

"an individual is socially excluded if he or she does not participate in key activities of the society in which he or she lives."

The activities he refers to are: consumption; production; political engagement; and social interaction. Therefore, the lack of participation in these activities contribute to social exclusion.

The European Commission, in the joint report by the Commission and the Council on social inclusion (2004) also provided definitions for social exclusion as well as social inclusion. In their eyes, social inclusion is a process that ensures greater participation in decision making which affects the socially excluded individuals lives as well as fundamental rights. Also, it fortifies the access by those at risk of poverty and social exclusion to opportunities and resources necessary to participate fully in economic, social and cultural life. On the other hand, the European Commission understands social exclusion as a process whereby an individual is pushed to the edge of society, therefore being prevented to participate in social events fully by virtue of their poverty, or lack of basic competencies and lifelong learning opportunities. This creates a gap between the person and certain opportunities like jobs, education and social and community network activities. Socially excluded people tend to have less access to power and decision making which makes them feel powerless and unable to take control over decisions that affect their daily lives.

The UK Social Exclusion Unit SEU (2003) reaffirms these ideas by stating that social exclusion happens when a handful of problems are casted upon certain people or areas, problems such as poor skills, low incomes, high crime rate, poor health, unemployment and family breakdown.

\subsubsection{Mobility and transport related social exclusion}

It is now possible to allow mobility and transport subjects to be introduced and taken into consideration. These terms are directly related to social exclusion and many studies have shown the impact that transports represent on the social exclusion subject. Mobility is a tool that must be used by someone in order to reach certain goods, services and activities (Lucas et al., 2016).

Kenyon et al. (2002) declares a definition for transport and mobility related exclusion:

Mobility-related exclusion is "the process by which people are prevented from participating in the economic, political and social life of the community because of reduced accessibility to opportunities, services and social networks, due in whole or in part to insufficient mobility in a society and environment built around the assumption of high mobility." 
Church et al. (2000) made clear seven specific transport-based exclusions that are directly related to social exclusion and that prove that social exclusion is a problem with a multidimensional nature. These seven categories are:

- geographical exclusion: impediment of utilizing transport services because of the area a person lives;

- exclusion from facilities: key facilities are located far from where a person lives;

- economic exclusion: the cost of travel prevent a person from accessing the transport system and therefore is not able to reach certain facilities;

- time-based exclusion: reduced time available for travel (interchangeably used in the literature as time-poverty);

- fear-based exclusion: the fear for personal safety may induce "hesitant to get" out behaviours and therefore transports or public spaces are not used;

- space exclusion: prevention of access to certain groups in some areas, e.g gated communities or first class waiting rooms at stations;

- physical exclusion: physical barriers, lack of disabled facilities or information, obstruct the access to transport services.

This list gives an overall view of how transport-related social exclusion is composed, but lacks on expressing in which layer of activity it occurs and gives no solutions to solve each feature (Lucas, 2012). It is possible to see that lack of information also promotes physical exclusion, Davies (2001) states that product information should be perceived as informative as a basic consumer right (e.g facts presented in a straightforward, easily readable, and clear way). This author also mentions dimensions of perceived information (PIQ) which is defined as a set of judgement criteria, or dimensions, for evaluating the perceptions of product information; clarity, readability, accessibility and relevance are the main dimensions of PIQ (Davies, 2001). 


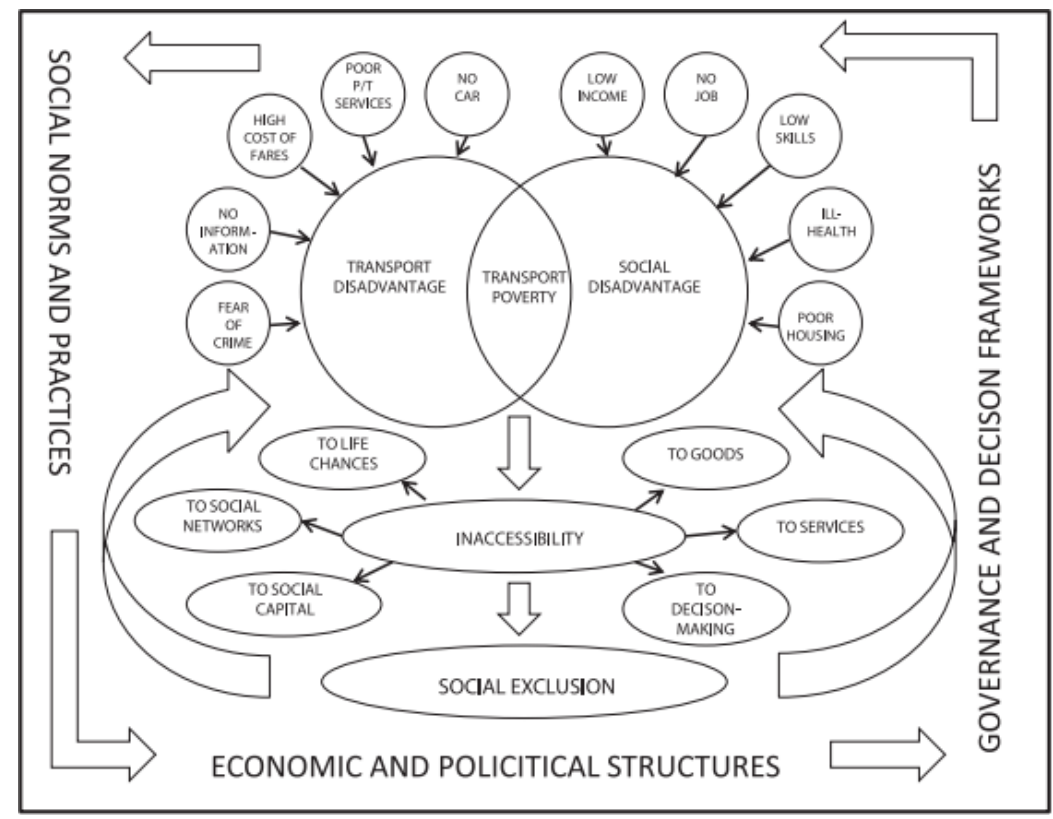

Figure 2.1: Differentiation of transport disadvantage, social disadvantage and social exclusion. Source: Lucas (2012)

Lucas (2012) discuss about the importance of establishing a difference between transport disadvantage and transport-related social exclusion, stating that these aren not necessarily synonyms, but the concepts interact directly and indirectly to cause transport poverty. Figure 2.1 illustrates the key interactions between these 3 concepts.

Mackett and Thoreau (2015) state various factors that can contribute to a transport related social exclusion as well as some references and facts to prove them, these factors are: income; disability; age; gender; ethnicity; cost; availability of transport; psychological barriers; physical barriers; facilities; and information.

Information is the main topic for discussion of this thesis, as poor travel information may lead to misunderstandings, lack of knowledge and, therefore, social exclusion. Nowadays, if an individual owns a smartphone, tablet, or any device with the Maps installed, he or she may easily use that device to create a route that provides the basic information needed to be able to reach the destination. However, not all socio-economic groups have sufficient income to buy a technologically advanced device, and some individuals have disabilities which makes many devices not suitable for their use (Mackett and Thoreau, 2015). Also, there is some information that is not being treated equally, for example, a person in a wheelchair will require an elevator to reach either the subway or the train. In many interfaces, that information is not exposed whilst being necessary.

\subsubsection{Identification of socially excluded individuals}

Cass et al. (2005) interviewed a number of local authority representatives in the UK with the intention of finding out what were their thoughts on social exclusion in relation to transport and what methods were used to assault this problem. The answers were inconsistent and different. It 
turns out the representatives had diverse views about the subject; some applied the term "social excluded" to specific groups, while others referred it to certain deprived areas (Cass et al., 2005), and it is in fact true that some groups are more affected by social exclusion than others (Lodovici and Torchio, 2015).

Lodovici and Torchio (2015) define poverty and social exclusion as interchangeable terms since they both affect the same population and groups. According to a study conducted by European Comission (2010), in Europe, especially in Hungary, Bulgaria and Romania, 90\% of the citizens perceive poverty to be a widespread phenomenon, this value being considered the highest registered. Meanwhile in Denmark, Cyprus and Sweden mark the lowest values as 38\%, 38\% and $33 \%$ respectively (European Comission, 2010).

Note that Table 2.1 shows a survey that was conducted to find out which groups were most at risk of poverty in different countries, which directly means at most risk of social exclusion, according to people beliefs. The unemployed group was the most noticeable, having the highest percentages in almost all countries. Lodovici and Torchio (2015), from a literature review point, write about the impact of the public transport system on socio-economic disadvantages. Children and young people, elderly, disabled, women, migrants and ethnic minorities, low-income and unemployed individuals, people living in rural and deprived areas are the ones at most risk, which goes into association with what is shown in Table 2.1. 


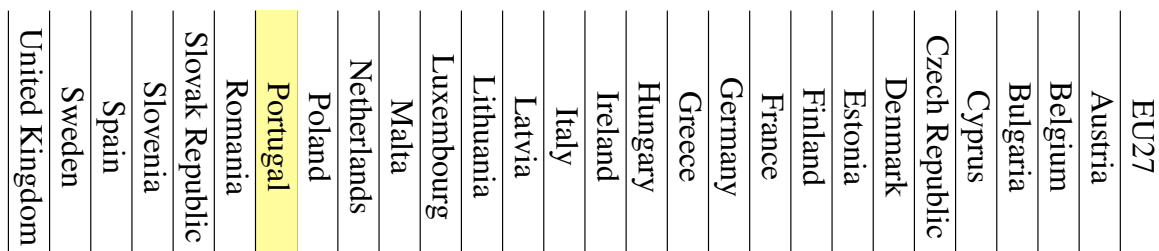

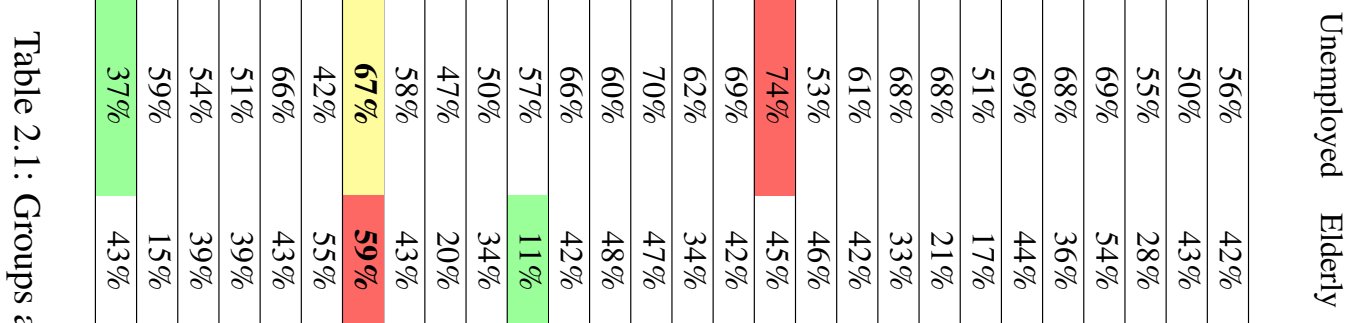

o

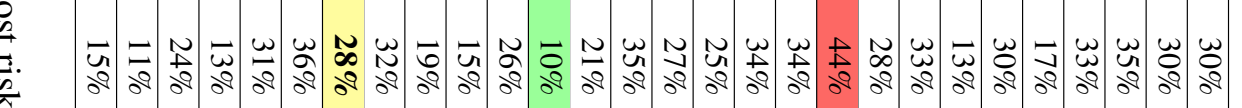

$\circ$

ב

$\stackrel{9}{2}$

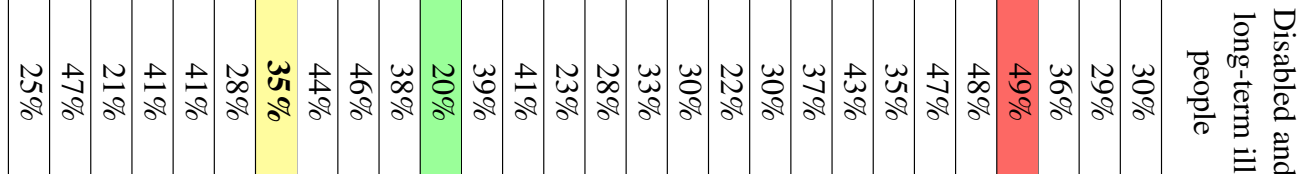

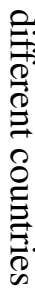

$\stackrel{2}{\varrho}$

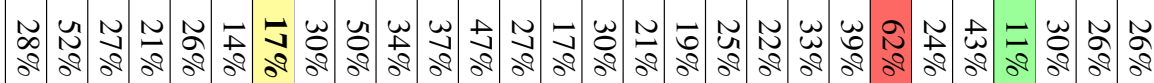

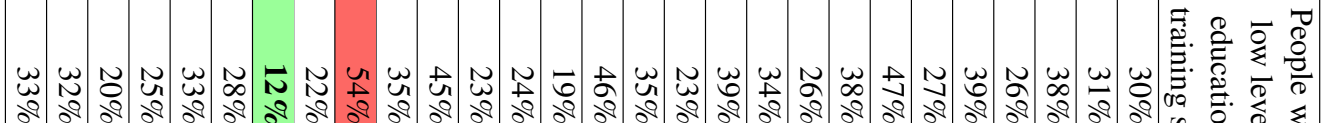

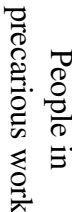

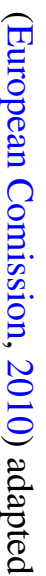

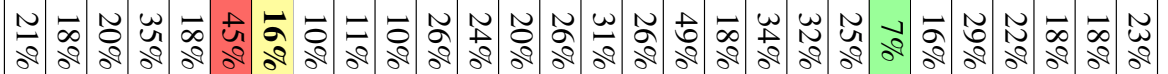
足:

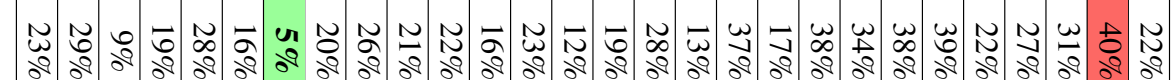

$\overrightarrow{8}$

竞

高.

के

芦芯

密

0
0
0

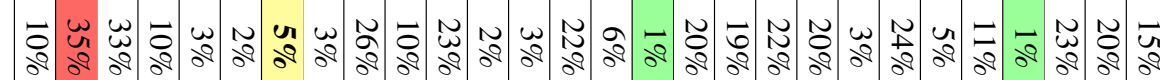

$\stackrel{\Omega}{\stackrel{2}{0}}$

空.

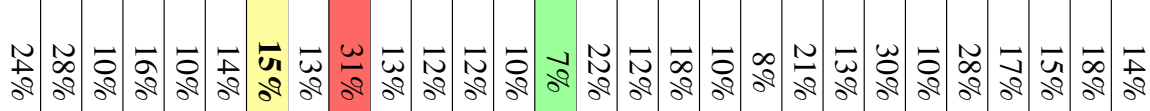

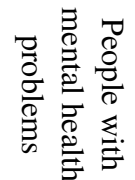




\subsection{Route planners}

\subsubsection{Concept}

Nowadays passengers want to be able to travel as fast, comfortable, safe and cheap as they possibly can, while at the same time being able to easily access certain core information about the trip (Ştefănescu et al., 2014). Houghton et al. (2009) state that it is now possible to apply advanced technology to collect more and better data, whose process of analysis is also enhanced to create an end result that is more efficient, effective and targets services for passengers. This technology is known as Intelligent Transport Services (ITS) and it has been around for many years, with recent developments. However, as Houghton et al. (2009) state ITS can sustain and demonstrate a fair number of helpful information:

- Enhanced transit/customer relationship management;

- Traffic prediction;

- Improved transport and traffic management;

- Integrated fare management;

- Traveler information and advisory services;

- Road user charging;

- Variable parking pricing.

The rapid growth of new technologies is radically changing the way the public transport sector operates, as it is now possible to replace the expensive infrastructures, which were once required, by a simple mobile device and online platforms (Ferreira et al., 2017). Technological advance has made simple but significant changes for bus passengers, for example, it is now possible to know the expected arrival time when waiting for buses. These applications can be called live bus arrival information and they support various benefits for users (Barber et al., 2018): decreased expected time; improved satisfaction with bus service; and positive impact on ridership. These applications can be entwined with trip planning apps and therefore providing expected arrival times for buses that an individual needs to catch in order to travel somewhere. A trip planner can be considered a smart travel assistance tool which can provide certain information to the passenger for a given origin and destination stops (Rout et al., 2013).

It is becoming a habit for human beings to be constantly online (Amador, 2014), whether indoors or outdoors, on smartphones or tablets or even laptop computers. The number of journey planning apps that currently exist is quite significant and they usually require the access to the internet, which by now should not propose any problems. 


\subsubsection{Existing work}

This section is meant to expose some of the applications that have been developed surrounding this theme thus far, as well as some of their main characteristics.

Manchester School of Architecture (2016) does a very general and good analysis of various journey planning apps. This work also tackles different high level features that journey planners should include, such as:

- Multimodal, which means the journey planner provides various options to choose from considering various methods of transportation e.g train, bus, subway and walking;

- Navigation, feature that most apps have, keeps track of the user's movement and provide navigation guidance;

- Real time information, which happens when an app and the device have built-in GPS navigation, henceforth users are notified about traffic conditions and re-route to avoid certain unpredicted delays. This information also includes arrival or departure times and line closures. Automatic re-routing to alternative paths or inform users about imminent departures are part of this type of system;

- Crowdsourcing data, a feature that allows users to contribute certain information to a system. When used properly, valuable location data can be collected and shared among other users who can respond accordingly;

- Personalisation allows users to meet their specific needs more efficiently as well as effectively. A good example of this feature is when an app is able to store a preset location for 'home' or 'work' based on a user's previous behaviour, or simply manually;

Table 2.2 shows the ranking of different and popular route planners separated by different factors such as Features, Usability and Popularity; note that the numbers represent the outcome from each evaluation criteria being 1 the highest/best possible outcome, and 20 the lowest/worst. To produce the overall ranking, each column is normalized for each evaluation with equal weighting. Considering all the apps included in this table, 5 of them were detached from the others in a positive way, bearing in mind a high level feature evaluation: Google Maps; TripGo; Here WeGo; Citymapper; and TfGM. The analysis was based on modes of transportation supported and identified features supported. 


\begin{tabular}{|c|c|c|c|c|c|c|c|c|c|c|c|}
\hline & & \multicolumn{3}{|c|}{ Features } & \multicolumn{4}{|c|}{ Usability } & \multicolumn{3}{|c|}{ Popularity } \\
\hline & & 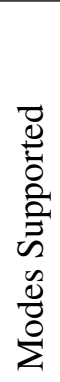 & 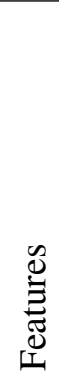 & $\begin{array}{l}\overline{\bar{d}} \\
\overline{0} \\
0\end{array}$ & 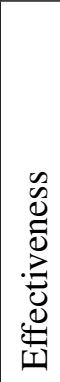 & 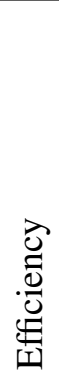 & 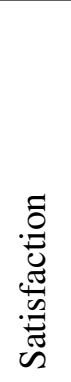 & $\begin{array}{l}\bar{\pi} \\
\overline{0} \\
\text { ठे }\end{array}$ & 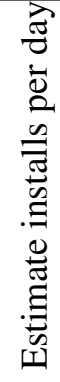 & 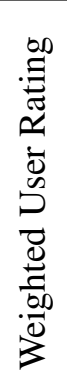 & 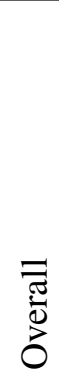 \\
\hline 1 & MAPS.ME - Map \& GPS Navigation & 5 & 3 & 8 & 4 & 17 & 13 & 16 & 5 & 1 & 2 \\
\hline 2 & Voyager: Route Planner & 5 & 5 & 12 & 5 & 20 & 12 & 17 & 11 & 5 & 9 \\
\hline 3 & My TfGM & 1 & 4 & 3 & 3 & 14 & 11 & 13 & 17 & 11 & 16 \\
\hline 4 & Maps - Navigation \& Transit (Google) & 1 & 2 & 1 & 2 & 5 & 7 & 7 & 1 & 3 & 1 \\
\hline 5 & MapQuest GPS Navigation \& Maps & 5 & 4 & 11 & 3 & 15 & 11 & 14 & 6 & 5 & 7 \\
\hline 6 & Citymapper & 2 & 2 & 3 & 1 & 2 & 1 & 2 & 10 & 1 & 4 \\
\hline 7 & Transit Directions by Moovit & 5 & 1 & 4 & 2 & 4 & 6 & 6 & 4 & 3 & 5 \\
\hline 8 & Transit: Real-Time Transit App & 4 & 3 & 7 & 2 & 7 & 2 & 4 & 9 & 4 & 8 \\
\hline 9 & TRAFI - Public transport app & 3 & 3 & 5 & 1 & 12 & 4 & 6 & 8 & 2 & 6 \\
\hline 10 & TripGo:Transit,Maps,Directions & 1 & 3 & 2 & 1 & 1 & 1 & 1 & 13 & 12 & 14 \\
\hline 11 & HERE WeGo - City Navigation & 1 & 3 & 2 & 3 & 6 & 8 & 9 & 3 & 2 & 3 \\
\hline 12 & Journey Planner (TFI) & 4 & 3 & 7 & 3 & 9 & 5 & 8 & 12 & 6 & 10 \\
\hline 13 & Offi . Journey Planner & 4 & 5 & 11 & 3 & 18 & 8 & 12 & 7 & 1 & 4 \\
\hline 14 & Maps, Navigation \& Directions & 5 & 4 & 11 & 5 & 19 & 14 & 18 & 2 & 5 & 5 \\
\hline 15 & Traveline GB & 5 & 3 & 8 & 2 & 3 & 3 & 3 & 15 & 8 & 12 \\
\hline 16 & London Journey Planner & 4 & 4 & 9 & 2 & 11 & 2 & 5 & 14 & 7 & 11 \\
\hline 17 & TRACKR FREE: Bus \& Train Times & 5 & 3 & 8 & 2 & 8 & 9 & 9 & 18 & 10 & 15 \\
\hline 18 & Tripotnik - Sustainable travel & 2 & 5 & 6 & 3 & 13 & 11 & 11 & 20 & 12 & 17 \\
\hline 19 & Merseytravel & 6 & 3 & 10 & 3 & 10 & 10 & 10 & 16 & 9 & 13 \\
\hline 20 & MOVESMART (Certh-iti) & 2 & 5 & 6 & 3 & 16 & 11 & 15 & 19 & 13 & 18 \\
\hline
\end{tabular}

Table 2.2: Ranking table of various trip planning applications (Source: Manchester School of Architecture (2016))

As Figure 2.2 shows, Google Maps owns a clean interface with simple but vibrant colours which provides a somewhat instinctively understanding of what is on screen and the usability of the app in general. Figure 2.3 demonstrates two important features that Google Maps possesses: Uber and Cabify linking and a history of places the user has been to in addition to saving a user work place and home as presets. It is worth noting that 8 out of the 20 apps stated in Table 2.2 are not multimodal, and 10 out of the 20 apps do not handle real-time information whilst Google Maps has both features integrated.

Concerning the Usability evaluation, as Table 2.2 attests, three main features have been considered: effectiveness; efficiency; and satisfaction. The top five apps in Usability are Citymapper, Traveline GB, TripGO, London Journey Planner and Transit. In regards to Usability, Manchester School of Architecture (2016) associates various core features that can greatly improve a user experience, namely: 


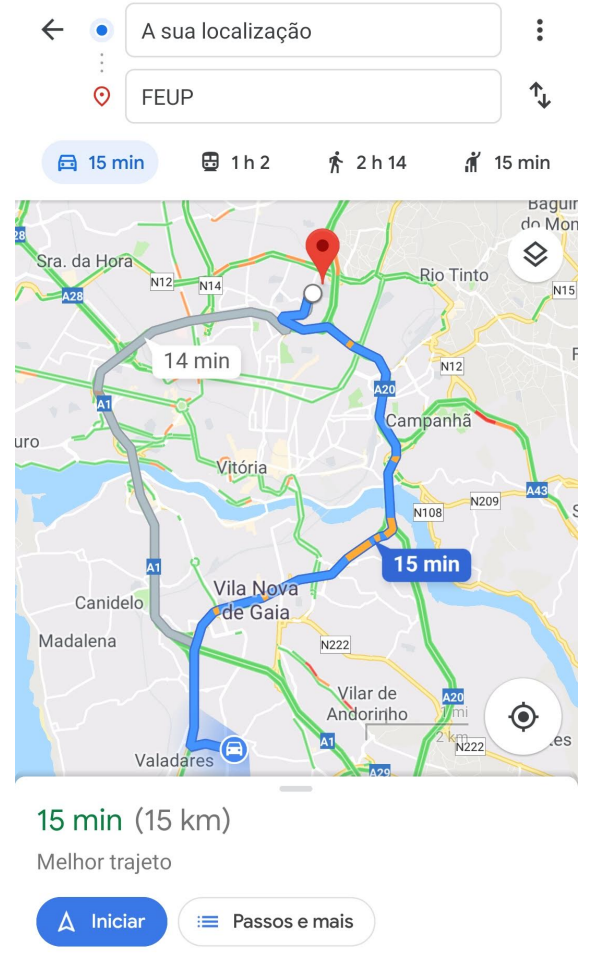

(a) Google Maps interface while using the driving feature

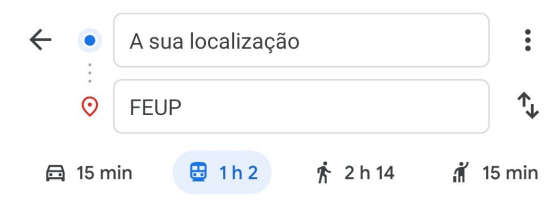

Partida: 3:03 da manhã - $\quad \because 9^{\circ} \quad$ Opções

A Estes resultados poderão estar incompletos - nem todas as empresas de transportes públicos nesta área forneceram informações.

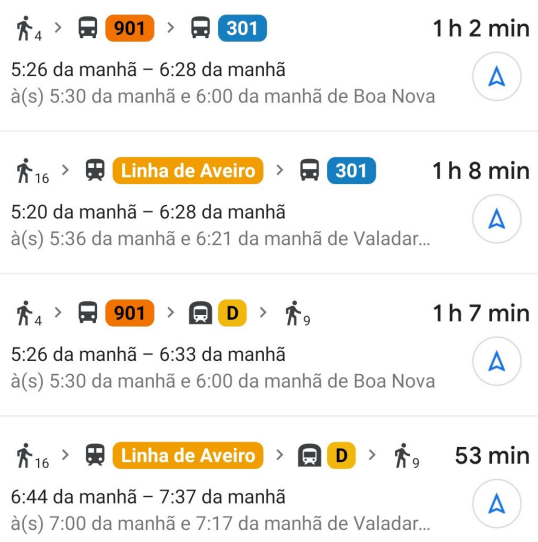

(b) Google Maps interface while using the public transport feature

Figure 2.2: Google Maps Interfaces (Part 1)

- Maps and Points of Interests (POI), which refers to the ability to retrieve a location input from a user and translate it to longitude and latitude coordinates, or it can be acquired from location information within predefined POI's. When using search feature, the predefined locations are able to be incorporated;

- Geocoding, feature that, in conjunction with auto-completion, allows a user to pick the required location from a drop down list, for instance. A list of previous selections within a search history is also included. In its essence, it facilitates the action of defining an origin and a destination;

- Time of Travel, feature that is extremely common and also important considering the fact that informs users about the amount of time the journey will take. Some route planners have a traffic dataset that incorporates estimated delays;

- Customization is also a great feature that an app should bear, taking into account it provides the users different options that are more suitable for each individual;

- Results display provides the user various journey options. Essentially, journey time and multiple-leg journey are the two most common results displayed. 


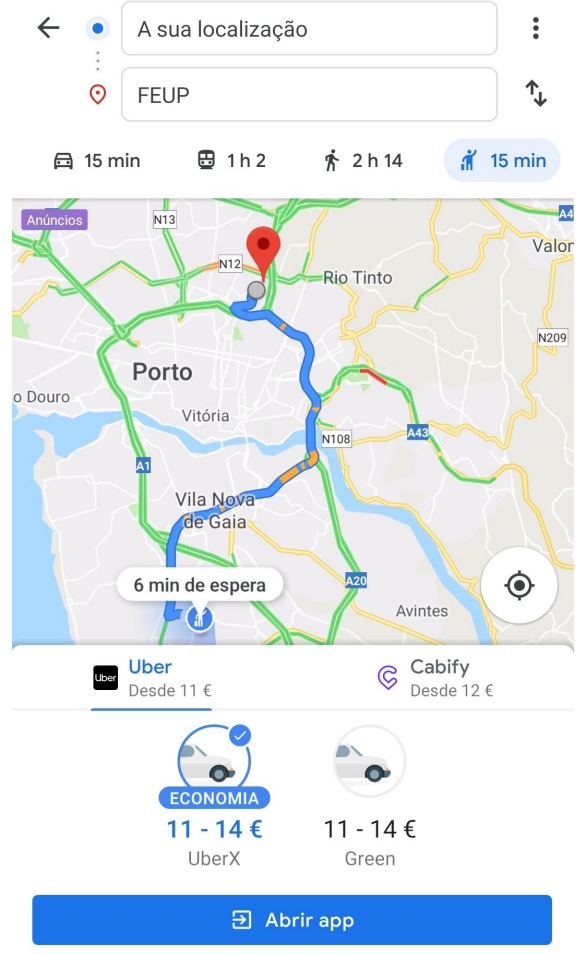

(a) Google Maps interface while using the uber/cabify feature

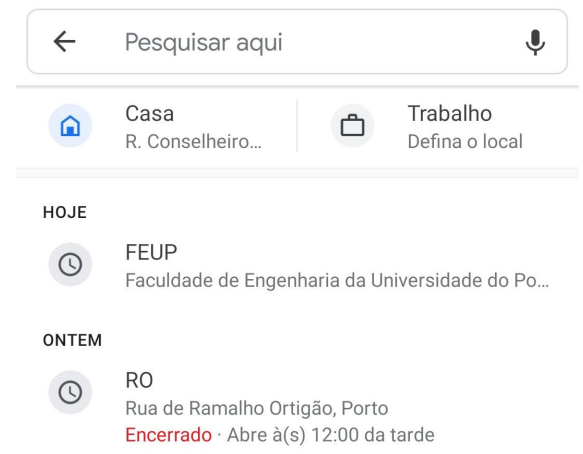

(b) Google Maps interface while checking a user history

Figure 2.3: Google Maps Interfaces (Part 2)

It is important to note that not all the applications included in Table 2.2 support all methods of public transportation that are common nowadays. For instance, 'MAPS.ME', 'Voyager' and 'Maps, Navigation \& Directions' do not own information regarding trains, trams, buses and others, therefore, no data about those methods of transport is disclosed to the user. Meanwhile, 'Transit: Real-Time Transit App', 'Journey Planner (TFI)', 'Offi - Journey Planner' and 'London Journey Planner' are able to provide information about trains, trams and buses, but they do not support information about car, walking or bicycle trips. Among all the applications that are stated in the table, only 'Maps' by Google, 'My TfGM', 'TripGo' and 'HERE WeGo' are the only ones that, in addition to being considered multi-modal, also manage to create viable travel routes utilizing car, walk, bicycle, train, tram, bus and other methods of transportation available (i.e. scooter, boat).

Citymapper is an excellent example of a new, solid and reliable route planner; its main mission consists in "Make Cities Usable", focusing on helping people get around cities while at the same time, reducing congestion and pollution. The app allows users to select a major city and view all options for public and private transportation within that area. In Figure 2.4 it is possible to observe two examples of user interfaces that Citymapper owns: the left one is what the user sees when he or she opens the application, and the right picture demonstrates various transportation suggestions to go from Praça do Rossio to Santa Apolónia.

It is important to notice the symbols that Citymapper uses for informing the user about possible trip routes by bus, car or bicycle, for example. In order to provide good discover ability of varied 


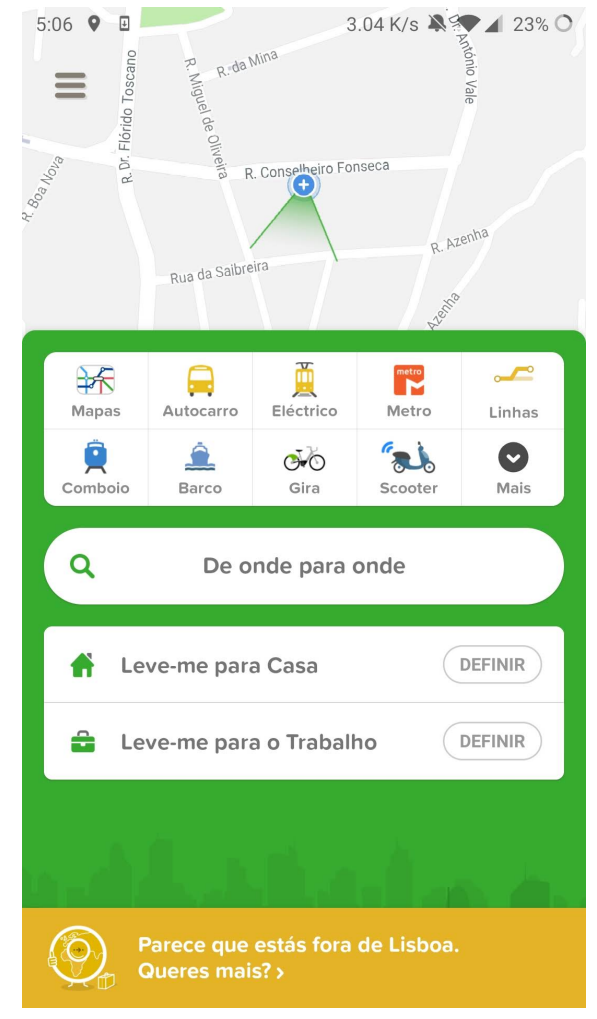

(a) Citymapper main interface

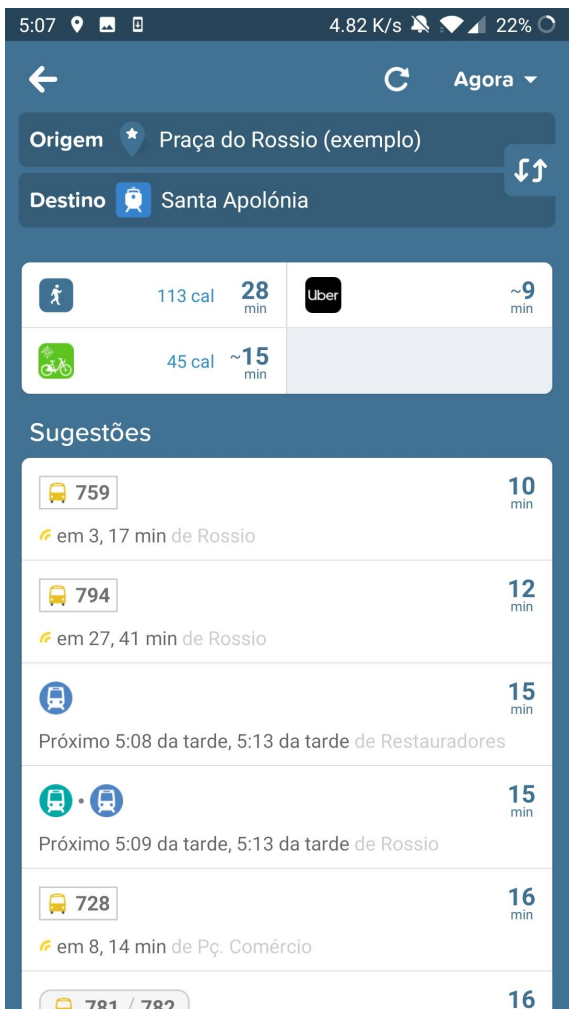

(b) Citymapper interface while choosing a transport option for a trip

Figure 2.4: Citymapper Interfaces (Part 1)

transport modes, the main page uses great visual illustrations that act as signifiers. It is clear to people without any visual or mental problems to realize which button to press, but that may not be the case if the user has one or more of those problems.

The colors and design on the interfaces shown in Figure 2.4 and Figure 2.5 are vibrant but also neutral, which provides a good contrast to the overall look, it is an appealing app to many commuters and explorers. The colors need to be tested in a group of socially excluded people to conclude if it needs tuning.

An application named MOVE-ME is not listed in Table 2.2, however, it is one of the main apps used by commuters in Portugal. The MOVE-ME project (www.move-me.mobi) consists of a mobile application that provides real time information to public transport users, including data from subway, bus and train schedules (Falcão and Galvão (2013)).

This app was was launched in 2012 and it has suffered a few updates on the interface and well as some heavy ones in updated public transport routes, specially regarding buses. It mainly focuses in the Metropolitan Area of Porto and Metropolitan Area of Lisbon. The system architecture of MOVE-ME is based on previously developed transport information services and its main data base is able to collect detailed information from various transport companies such as network details, schedules and real time data (Falcão and Galvão (2013)).

The MOVE-ME project had a successful launch and many people still use the app nowadays. 


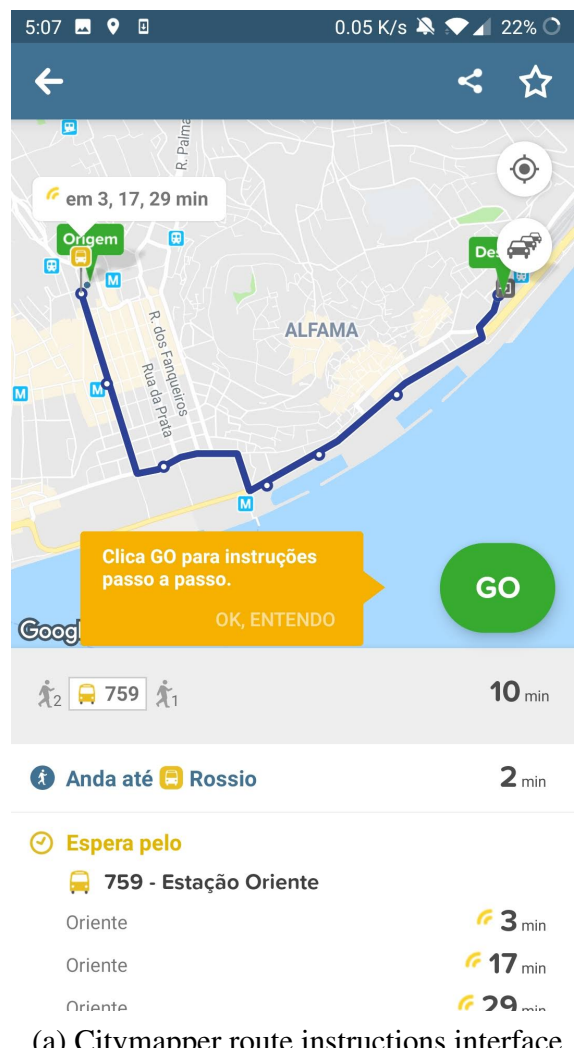

(a) Citymapper route instructions interface

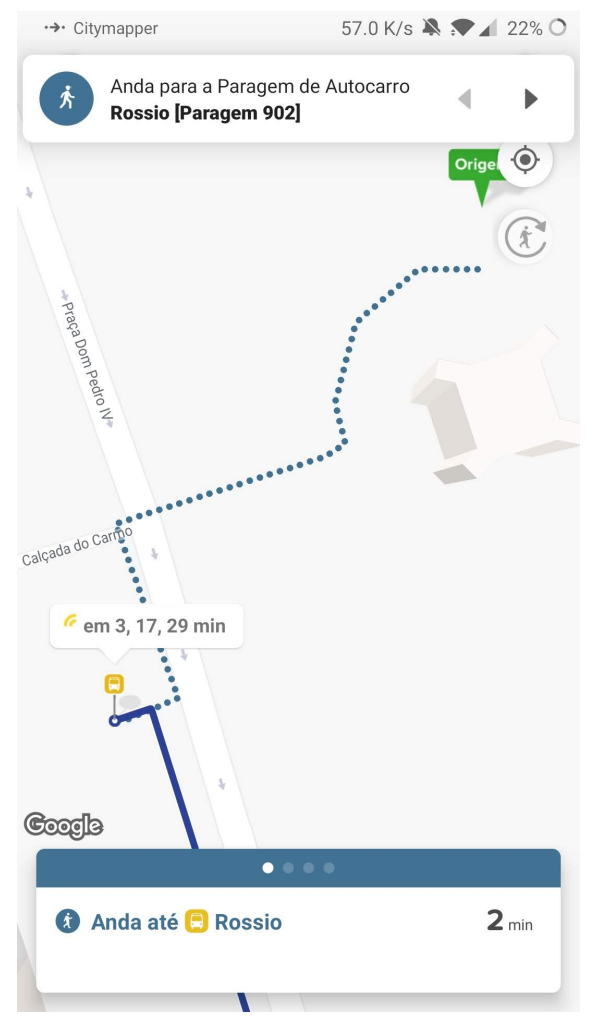

(b) Citymapper step-by-step instructions interface

Figure 2.5: Citymapper Interfaces (Part 2)

If the app was listed in table Table 2.2 it would most likely be evaluated with average scores regarding features and a good score considering usability tests as well as popularity. A prototype that could measure and share users emotional state was initially proposed, it could capture users effective state using a simple emotional model of travelling mood, with features that are based on Russell's circumplex of emotion. However, it seems like this prototype did not breakthrough since it is not implemented in the current app, although the concept is very interesting and worthy of research in future projects.

In Figure 2.6 it is possible to see the simplistic MOVE-ME main interface that didn't change too drastically over the years since the 2012 original launch. After a discussion with the whole team behind this project, we got to know a few curious and interesting facts, one of those is that the light blue color was quite a hard choice to make since it took a while for everyone to get to an agreement, the color was chosen over an inquiry that was taken by a substantial amount of people.

The picture on the right in Figure 2.6 represents an interesting feature that MOVE-ME owns, it locates POIs (Points of Interest) near the user location, if the user presses the yellow button down at the bottom a selector pops up, allowing the user to choose various radius considering the center being where he or she is located on the map, after picking the desired number a new interface appears, similar to the one that was showing before, but this time with arrows on the different POIs that can be encountered in the selected area, as shown in Figure 2.7. 


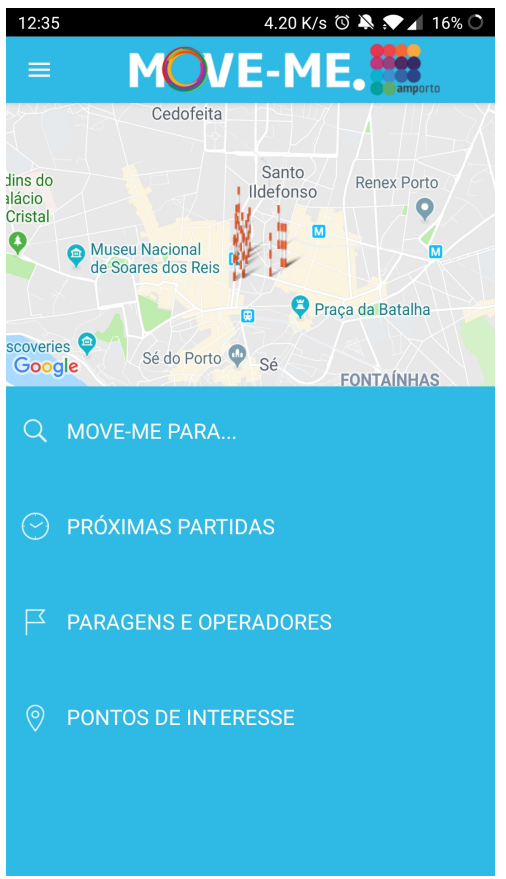

(a) MOVE-ME main interface

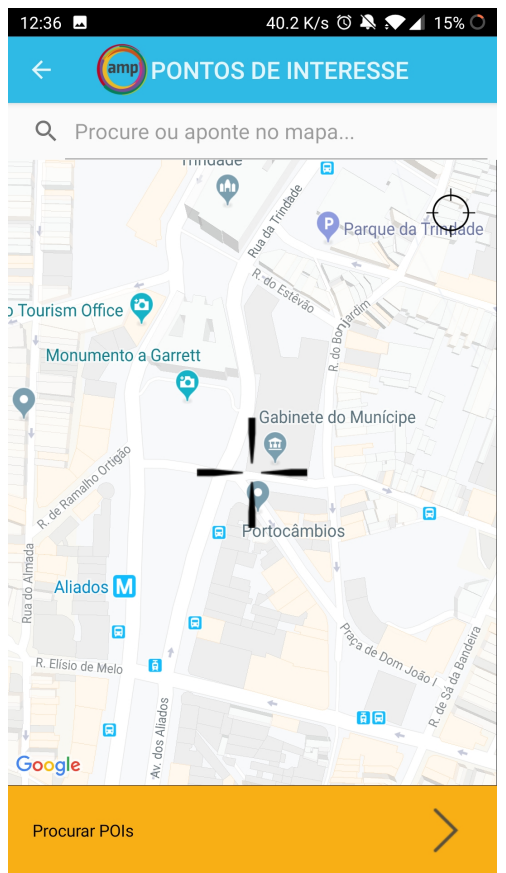

(b) MOVE-ME Points of Interest interface

Figure 2.6: MOVE-ME Interfaces (Part 1)

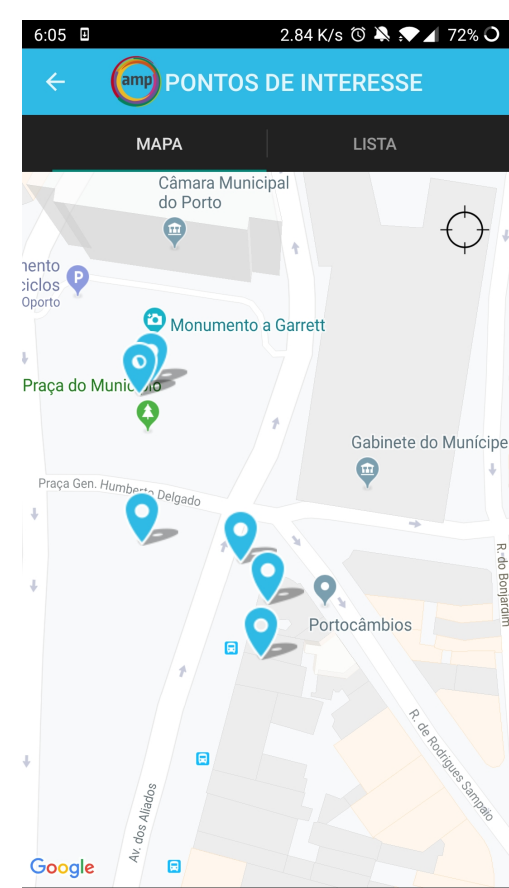

(a) MOVE-ME with various Points of Interest selected

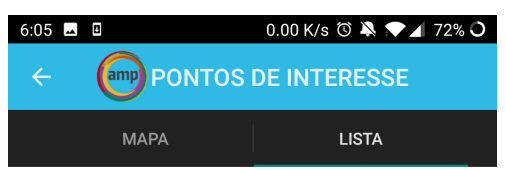

Gabinete do Munícipe

Hotel Chique

Hotel Paulista

Miradouro - Torre da Câmara Municipal do Porto

Paços do Concelho

Associação Humanitária Bombeiros Voluntários do Porto

(b) MOVE-ME list of POIs nearby a user location

Figure 2.7: MOVE-ME Interfaces (Part 2) 


\subsubsection{Conclusion}

It is plausible to say that none of the applications introduced on Table 2.2 have specific features that take into consideration particular needs that socially excluded people bear. As stated in section 1, a substantial amount of groups are recognized as excluded when it is taken into consideration how public transports work in the current days.

In order to promote social inclusion, this work aims to elaborate and mention new features, resorting on new and simple interfaces that journey apps can use to improve these groups experience in public transportation. These features vary from each excluded group so, in order to simplify, there will be a focus group, which will be discussed in the next chapter. 


\section{Chapter 3}

\section{Problem characterization and approach}

This chapter will focus on discussing several topics that should be approached before developing any kind of interface. The first topic identifies the socially excluded group that was selected and the reason behind it. The second topic will focus on what information should be disclosed to the said group in order to promote social inclusion in public transportation. The third topic discusses about how the design of an interface can affect the individual using it and how to actually develop one. The last topic will cover the usability term, which is prominent in the process of interface design.

\subsection{Introduction}

In general, information that is perceived by citizens is differently processed depending on various factors, normally according to their socio-economic context and experience. This means that some groups will be marginalized and therefore considered socially excluded. In chapter 2 various groups that are considered socially excluded nowadays are exposed as well as, frequently, public transportation methods and applications are not sophisticated enough to solve the marginalization problem that it is being promoted.

Software applications that support urban mobility, namely route planners, should have this in consideration but instead, as software developers aim for bigger, general and more lucrative markets, many of the apps that are being produced do not address the peculiar requirements that people who are not socially included tend to own. Technology enables new opportunities in form of social interaction or direct access to information anytime, anywhere (Wang and He (2015)). These two aspects are extremely important in this work, since it proves that new software applications that disclosure information to the user, specially those intertwined within the public transportation subject, may decrease the number of socially and transport excluded people and therefore encourage social inclusion.

The discussion that arises from the idea of developing a new journey planner application, whom excluded people can benefit from, mostly concerns to which information is decisive to reveal to the user, how will this information be revealed and how will the interface be designed in 
order to be as clear as possible to the user, which means, for instance, to not cause any visual or other type of confusion.

\subsection{Focus group}

As it was previously stated in chapter 2, the elderly group is considered extremely prominent within the social exclusion subject (Lodovici and Torchio (2015)), that being the case, it was the chosen focus group for this work. However, this project aims to help socially include as many groups as possible, henceforth, the disabled and people with reduced mobility (i.e. pregnant women, cane or crutches users, people with visual problems, the handicapped, etc.) will also be at target.

As living conditions, standards and medical progress improves, people's life expectancy is increasing everywhere around the world. In 2017, 962 million people were 60 years old or over, which is substantially more than in 1980, where the numbers were around 382 million worldwide. The alarming number comes a few years later, 2.1 billion people are expected to be 60 years old or over in 2050, that is almost one third of the current earth population. Moreover, in 2030, the number of older people in the world is foreseen to surpass children under the age of 10 (1.41 billion and 1.35 billion respectively) (United Nations and Affairs (2017)).

Mackett (2014) states that as people age, there is an increased risk of mental health problems that follows, adding this to physical and sensory deterioration like vision loss, reduced mobility and hearing problems, the elderly face various barriers that might seem quite ordinary for a youngster or a person with good mobility.

Soltani et al. (2012) assures that public transport terminals lack good design and facilities, promoting less accessibility, specially for groups with mobility related issues. However, the development of information interfaces that are able to demonstrate certain areas of the terminal would have a major impact on the accessibility problem, given that it would help the users get a better orientation through the terminal.

A number of age-related changes and what consequences they bring into mobility have been recognized by various researchers. Reduced flexibility and strength; impairment of visual perception; and an increase in bone fracture vulnerability are a few examples. A survey conducted by infas \& DLR (2008) found out that, as people get older, there is a tendency to decrease driving habit, which promotes an increase in walking and public transport use, particularly after the age of 74. Consequently, the quality in public transports is a key factor regarding the mobility of the elderly. With the intention of enhancing that experience, there should be an effort to not only focus on the physical realm (e.g. better seats, air conditioner, better bathrooms), but also on software applications, simply because of the fact that they can provide exclusive and important information to the user. 


\subsection{Public transport information}

Aging related diseases can provoke sever damage in the humans basic organs and lead to defectiveness such as: hearing loss (presbycusis); decrease of visual acuity (presbyopia); muscle loss; lower walking speed; mobility disability; cognitive aging; dementia; and depression (Efraim Jaul, 2017). This means that physical obstructions as be steps, edges, steep lopes or simple obstructions on the pavement take a role on stopping the elderly and mobility reduced people from accessing public transports. These aspects must be considered for the future interfaces that will be developed based on the mock-ups that this work will build.

Follmer et al. (2008) conducted a survey that affirmed that shopping and leisure are the two most prominent motives for people above the age of 60 to travel. Many facilities such as food shops, libraries and town centres are believed significant for this group to have easy access to, being the healthcare services considered extremely important in this matter (Hounsell et al. (2016)). However, the information must be provided according to the needs of each profile. Fontes et al. (2018) demonstrate a simple example of the information that can be divulged to a certain user in a journey planner application by utilizing illustrative cases. This work might use that idea in order to simplify the understanding and promote examples of information that should be given to socially excluded people.

With these two important factors in mind, it is possible to understand slightly better the information that should be exposed to the group that is being taken into consideration, which is the elderly and the people with reduced mobility. Additionally, this data must be concise and clear, so the user won't have any problem perceiving the information. Hounsell et al. (2016) state that a wide range of information may be needed to attend the user necessities, namely:

- Bus and tram networks and routes;

- Stop locations, like bus stops, in order to promote a better overall intermodal experience;

- Schedule timetable of all the PT services, including weekdays, weekends and holidays;

- Ticket price for each trip;

- Method of payment;

- Physical requirements to use the PT.

All the types of information stated above can be considered significant but, at the same time, it exists several levels of utility that are directly related to each individual's needs, for example, a commuter with reduced mobility is particularly interested in the accessibility of the vehicles (e.g. if it has ramps, seat belts) as well as a method to buy a ticket online in order to reduce as much walking as possible. On the other hand, a user with sight problems might have a hard time seeing the letters or numbers and also colors, so the information has to be provided in a simple and intuitive way, utilizing icons and distinct colors to improve contrast, in this case the information 
that would matter the most would be, for instance, if there are any crosswalks near the stop station with an integrated sound system, or which direction to take after leaving the subway to go to the nearest elevator or automatic stairs.

This work will not only have in consideration the information that Hounsell et al. (2016) presented, but it will also try to include other types of data that may be essential, such as a portion of a map containing the stop station, to ensure that a user is able to see the crosswalks, traffic lights, elevators, stairs and ramps nearby.

\subsection{User-centered design}

A human-centered design consists of an approach to interactive systems development that focuses on making the systems usable and useful in order to provide a good service to the user needs and requirements. This enhances efficiency as well as effectiveness of the interface and promotes well-being, satisfaction, accessibility and sustainability to the user (SAITO and OGAWA (2011)).

The standard known today as ISO 9241-210 aims to ensure that the design created for an interface is user-centered, it consists of 6 principles (Travis (2011)):

- The design is based upon an explicit understanding of users, tasks and environments - this principle affirms that in order to produce a good outcome, it is needed to understand the users, what they want to do with the system and the environment in which the system will be used.

- Users are involved throughout design and development - this means that it is important to include the users in the development process and not only in a focus group at the beginning, and in a survey at the end. However, this work will not have this principle into account because it lacks a steady group of people to include in the process, there will be a focus group and a survey to acquire information to help develop the mock-ups.

- The design is driven and refined by user-centred evaluation - this states that usability testing should be included in the design process, despite that, as it was stated before, there is not a solid group of people who are integrated in the project, therefore this principle, as important as it is, will be skipped.

- The process is iterative - It is important to develop and design the mock-ups with the idea that it is quite impossible for a user to explain what they want from a system. It is required to show people examples of interfaces that were already developed and begin to improve from there.

- The design addresses the whole user experience - making things simple is not just what usability is about, it requires other aspects such as perceptual and emotional that are typically associated with user experience. 
- The design team includes multidisciplinary skills and perspectives - in a team, it is necessary to include a wide rage of views to produce the best outcome.

It is should be mentioned that ISO 9241-210 is considered an evolution from another standard called ISO 13407, which had the same objectives as the newer version, being a description of good practice in user centered design. It was used to provide guidance on design activities that occur throughout the life cycle of human-machine systems. The main goal of this standard is to guarantee that the development and use of these systems take into consideration the needs of the user.

In Figure 3.1 is it shown the interactive and iterative process that ISO 13407 strictly follows, it is composed of five stages. The first one states that it is important to collect relevant data in the context of where the system will be used. The second phase is to formulate the requirements needed for the development of the product. In the third stage it is emphasized how important it is to create simulations and mock-ups to acquire feedback from the users. The last stage the work that has been developed is confronted with all the requirements, in order to find defects and try to create the best solution for the system.

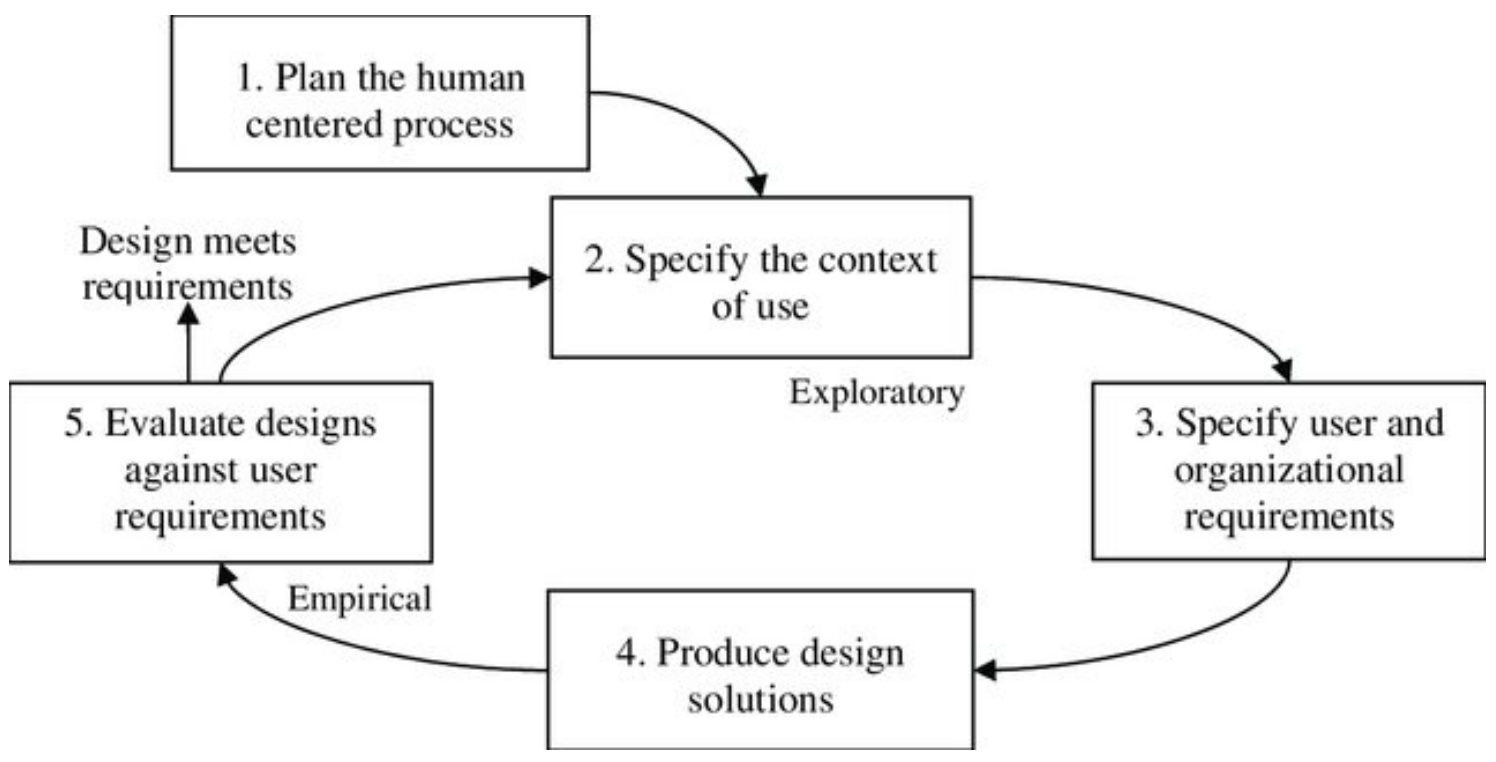

Figure 3.1: ISO 13407 interactive design process.

All these principles will serve as recommendations in this project's development, however, as stated above, some will not be able to be applied, therefore, with the finality of creating the best possible outcome with the resources that were allocated to this work, three main steps were selected:

1. Requirements elicitation - recognize, analyze and choose which group to focus was part of the project. In chapter 2, section 2.2, it is possible to find all of the groups currently in, or in risk of, social exclusion. The people with reduced mobility, specifically the elderly and 
the disabled were chosen. In this step, there was also a need to do a requirements elicitation through an inquiry and interviews.

2. Interface development - this phase represents the design of the mock-up interfaces, taking into account the requirements that were dictated by the previous step.

3. Validation - usability and design evaluation of the interfaces developed. This was done by conducting an inquiry to the population and a 1 hour session with experts in application development to public transports.

\subsection{Usability}

The usability of an interface is closely associated with how easy it is for a user utilize it, it can be considered a quality attribute. Nielsen (2012) states that usability can be defined by 5 quality components:

- Learnability: How easy is it for users to accomplish basic tasks the first time they encounter the design?

- Efficiency: Once users have learned the design, how quickly can they perform tasks?

- Memorability: When users return to the design after a period of not using it, how easily can they reestablish proficiency?

- Errors: How many errors do users make, how severe are these errors, and how easily can they recover from the errors?

- Satisfaction: How pleasant is it to use the design?

He also talks about another quality attribute, namely utility. it is important to make a remarkable distinguish between utility and usability: the first one is referred to the design's functionality, and it has to answer the question: "does it do what users need?"; the second one, as stated above, basically refers to how easy and pleasant it is to use the features that the interface provides.

This work will focus solely on the usability of the mock-up interfaces, which means that, if an application is developed utilizing the interfaces created by this project, these should be easy and pleasant to use.

In a more recent document, 9241-11 (2018) has stated that "usability is a more comprehensive concept than is commonly understood as "easy-to-use" or "user friendliness"". Also, in the same document, usability relates to the outcome of interacting with a system, product or service, and it is not an attribute of a product. They also affirm that usability is relevant to a couple things, such as:

- Regular ongoing use, to enable users to achieve their goals effectively, efficiently and with satisfaction; 
- Learning, to enable new users to be become effective, efficient and satisfied when starting to use a system, product or service;

- Infrequent use, to enable users to be effective, efficient and satisfied, with the system on each reuse;

- Use by people with the widest range of capabilities;

- Minimizing the risk and the undesirable consequences of use errors; and

- Maintenance, in that it enables maintenance tasks to be completed effectively, efficiently and with satisfaction.

Additionally, 9241-11 (2018) state that usability is prominent when designing or evaluating interactions with a certain system, service or product, with the finality of: development; procurement; review or comparison; and marketing and market research.

In this line of thought, and as it was stated before, the use of usability in this project will be towards developing mock-up interfaces that are easy to use, pleasant and simple with the goal of obtaining the maximum usability. 


\section{Chapter 4}

\section{Requirements elicitation}

This chapter will cover in detail how the requirements for the development of the mock-up interfaces were achieved. The sections ahead will analyse the results of several interviews and of an inquiry that were conducted with and without mobility disabilities that utilize public transports and own a smartphone.

\subsection{Introduction}

In chapter 2.3 were stated a few ideas referring to what kind of information is lacking in public transports that should be disclosed to mobility reduced public transport users. Nonetheless, most of these ideas are somehow subjective and not deepened enough to truly understand what is in fact missing in the information that is currently being spread to the travellers. For instance, Hounsell et al. (2016) state that bus networks and routes is essential information to provide older people, but in fact, that type of information is significant to any individual who utilizes public transports.

The real problem that is being treated here is: how that information should be handled and provided in order to be easily perceived. Therefore, the interfaces should not, for example, merely describe a bus network and the fastest route, as a matter of fact, equivalent to what Schlingensiepen et al. (2015) state, they should provide the traveller information about routes that meet their individual capabilities, needs, preferences and restrictions; these range from avoiding overcrowded buses to the inability of stair usage or simply having trouble understanding complex subway, bus or train stops.

After understanding what kind of information is lacking in route planners towards socially excluded groups in public transports, namely the ones with with reduced mobility, it is important to point out, in an initial proposal, what kind of requirements the interfaces should bear. Thus combining what Hounsell et al. (2016) and Schlingensiepen et al. (2015) stated, the conclusion was:

1. Vehicle - besides simply informing at which times the public transport arrives in each travel route, it is important to establish differences in the type of vehicles that are touring through these same routes; this means that there should be a focus on providing information about 
the public vehicles that, for instance, pass through a certain bus stop, considering that these may or may not have the proper equipment for wheelchair users.

2. Stop/station - additionally to what is referred in the first requirement, it is crucial to help people with reduced mobility locate themselves in subway stations or other locations that are part of the journey they're currently in, for example, in which side of the street is the stop; therefore, information about how to get to a certain station and, if needed, where to go once inside it will be present in the interfaces.

3. Pavement - while trying to access a station or moving inside it, information such as the location of automatic stair cases, elevators, bathrooms, ramps, steps and crosswalks with light and sound signals need to be considered for people with reduced mobility.

4. Schedule - when travelers are on a station/stop waiting for a public transport or already in a vehicle they should be warned about multiple events that are happening or will happen in a near future, for example when to leave the vehicle, which stop comes next, how much time until the connecting vehicle arrives and which vehicle to enter and when.

5. Ticket price and purchase - this requirement speaks for itself; if a person is able to purchase a ticket in an app, it will reduce moving.

These will be the information requirements to apply in the interfaces that will be developed.

Overall, if these features were to be implemented in a journey planner at this point in time, the app would have a great chance of succeeding within the groups with difficulties in locomotion.

\subsection{Data collection}

We collected data from public transport users through interviews and an inquiry. Data collection was performed in a public transport network from a medium sized metropolitan area (Porto, Portugal). This network is distributed along $1,575 \mathrm{~km} 2$ and split into 26 zones, it serves 1.75 million inhabitants. The network is based on an intermodal system that includes: 126 buses lines (urban and regional), six subway lines, one cable line, three tram lines and three train lines (TIP, 2015). Sections 4.2 .1 and 4.2.2 presents the design of the interviews and the inquiry respectively.

\subsubsection{Interviews}

The interviews were carried informal and anonymous to travellers from public transport of the Metropolitan Area of Porto, these. Two main requirements for carrying the interview were defined: the first one being the use of public transports and the second one being the use of a smartphone. All participants received information about the purpose and aims of the study and signed an informed consent form. 
The questions of the interviews were grouped in two main groups: (i) individuals personal use of public transport; and (ii) experience of using a route planning application and the script was as follows:

1) Which modes of public transportation do you utilize and how often?

2) What is the average time of each trip?

3) How do you get information about the schedule?

4) Name one positive and one negative factor about public transports.

5) Do you utilize a route planning app?

6) If the individual said no to question 5 , then:

(a) For any specific reason?

(b) What information would you like to receive in order to make use of a journey planner?

7) If the individual said yes to question 5, then:

(a) Which application do you use?

(b) Which information do you retain as most important?

(c) What attracts you the most about the design?

(d) Which features do you consider very important in the app?

(e) Which features would you like to see included in the app?

The first four questions were made with the intent of testing the waters, with the finality to understand if the person had experience and some sort of criticism towards public transports. The answer to question number 5 indicated if the person made use of a route planning application; if the answer was no, then questions 6 a) and b) were proposed, otherwise questions 7 a), b), c), d) and e) were suggested. The questions 6 a) and b) had the goal of acquiring information about the reason behind the disuse of a route planning app, and what kind of changes the person considered fundamental that could be implemented in said application in order to make use of it. The remaining questions, namely 7 a), b), c), d) and e), were oriented towards understanding why the person used the app, what kind of use was being made of it, and lastly what information would the person like to receive, other than what was already being revealed. The last questions were the most important and were a decisive key factor in discovering more requirements that could be adjusted and implemented in the development of the interfaces.

Even though the interview followed a script, sometimes it was required to create simple imaginary scenarios to place the person in a situation where they did not know the route to a destination, all this to achieve a more developed answer in how they would use the application, more precisely what features would matter the most, what information they would seek and how they would like the information to be presented (i.e. icons or sentences). The scenarios were: 
- a new shopping mall just opened and the person is interested in seeing it, this scenario will allow us to extract information about which the person will use to find the route towards the mall. It will also inform us of which transports is preferable to the individual;

- it is summer, and on a holiday the person decides he/she wants to go to the beach. Normally, summer weather is hot and many people tend to use public transports to visit the beach for refreshment, the information we are looking for with this example is, in people's opinion, which transports would be more suitable for trips in a heat climate;

- a trip to work was also a scenario that had the finality of knowing what transports people use the most, and what bothered them while in that trip (i.e. overcrowd, loudness, heat, etc.).

\subsubsection{Inquiry}

The inquiry that was made was composed of four short sections, namely:

1. General approach and basic requirements;

2. Route planning usage;

3. Application disusage;

4. Application improvement.

The first section was composed of questions that had the intent to filter if the user met the base requirements needed to answer the inquiry, i.e. to use public transports and a smartphone. After answering the first section, the person would be directed to section two, which was composed of only one question which had the finality of letting us know if the person used any application capable of route planning, checking schedules and ETA's within the public transport theme. The third and fourth sections appeared depending on the answer to the previous question in section two, that is to say if the person did not make use of an application it would be directed to the third section, otherwise, section four would appear. The third section had the objective to understand why was the person not making use of a route planning application (or just to check schedules and ETA's), and if it could provide feedback on what features and information would be important to implement in these apps so that it would make the person start using them.

The inquiry can be found in Table 4.1, where the questions that have "-" as possible answer were open questions and the all the others were either multiple choice or single choice. The most important parts of the inquiry are the third and fourth sections, which were created to understand why people use or not use route planners and if they have any kind of suggestions and ideas related to information and features that can be implemented in future software developments. 


\begin{tabular}{|c|c|c|}
\hline Section & Question & Options \\
\hline \multirow{28}{*}{1} & \multirow{5}{*}{ Which age range do you belong to? } & $<30$ years old \\
\hline & & $30<=40$ years old \\
\hline & & $40<=50$ years old \\
\hline & & $50<=60$ years old \\
\hline & & $>60$ years old \\
\hline & \multirow{2}{*}{ Do you use a smartphone? } & Yes \\
\hline & & No \\
\hline & \multirow{4}{*}{ With what frequency do you use public transports? } & Daily \\
\hline & & Sometimes per week \\
\hline & & Sometimes per month \\
\hline & & I do not use public transports \\
\hline & \multirow{5}{*}{ Which transports do you utilize? (Multiple choice) } & Bus \\
\hline & & Train \\
\hline & & Subway \\
\hline & & Private vehicle \\
\hline & & Others \\
\hline & \multirow{2}{*}{$\begin{array}{l}\text { Do you have any kind of physical, sensory } \\
\text { or cognitive deficiency? }\end{array}$} & Yes \\
\hline & & No \\
\hline & \multirow{4}{*}{ Average time per trip? } & $<10$ minutes \\
\hline & & $10<30$ minutes \\
\hline & & $30<60$ minutes \\
\hline & & $>60$ minutes \\
\hline & \multirow{5}{*}{$\begin{array}{l}\text { How do you obtain information about schedules? } \\
\text { (Multiple choice) }\end{array}$} & Mobile app \\
\hline & & Website \\
\hline & & Bus stops \\
\hline & & I do not need to know \\
\hline & & Others \\
\hline & Indicate 1 positive and negative factor about public transports. & - \\
\hline \multirow{2}{*}{2} & \multirow{2}{*}{ Do you use any app to route plan or check schedules? } & Yes \\
\hline & & No \\
\hline \multirow{2}{*}{3} & What is the reason for the disuse of an app related with public transports? & - \\
\hline & Indicate 2 features that would make you use the an app. & - \\
\hline \multirow{10}{*}{4} & Which application related to public transports do you utilize? & - \\
\hline & \multirow{5}{*}{$\begin{array}{l}\text { Which information do you consider most important in the app? } \\
\text { (Multiple choice) }\end{array}$} & Schedules \\
\hline & & Prices \\
\hline & & Routes \\
\hline & & Delays \\
\hline & & ETA \\
\hline & What other information do you consider important? & - \\
\hline & What attracts you the most in the design of the app? & - \\
\hline & What do you dislike the most about the design of the app? & - \\
\hline & Which features do you consider the most important in the app? & - \\
\hline
\end{tabular}

Table 4.1: Inquiry developed 


\subsection{Data evaluation}

\subsubsection{Interviews}

Ten interviews were carried out to travellers from public transport of the Metropolitan Area of Porto. All the interviewees were women, for no specific reason, and were at least 60 or more years of age. Although none of the individuals made use of a wheelchair, most of them had reduced mobility due to fatigue or aging. In Table 4.2 and in Table 4.3 we can observe the answers of the first five and last five interviewees, respectively. 


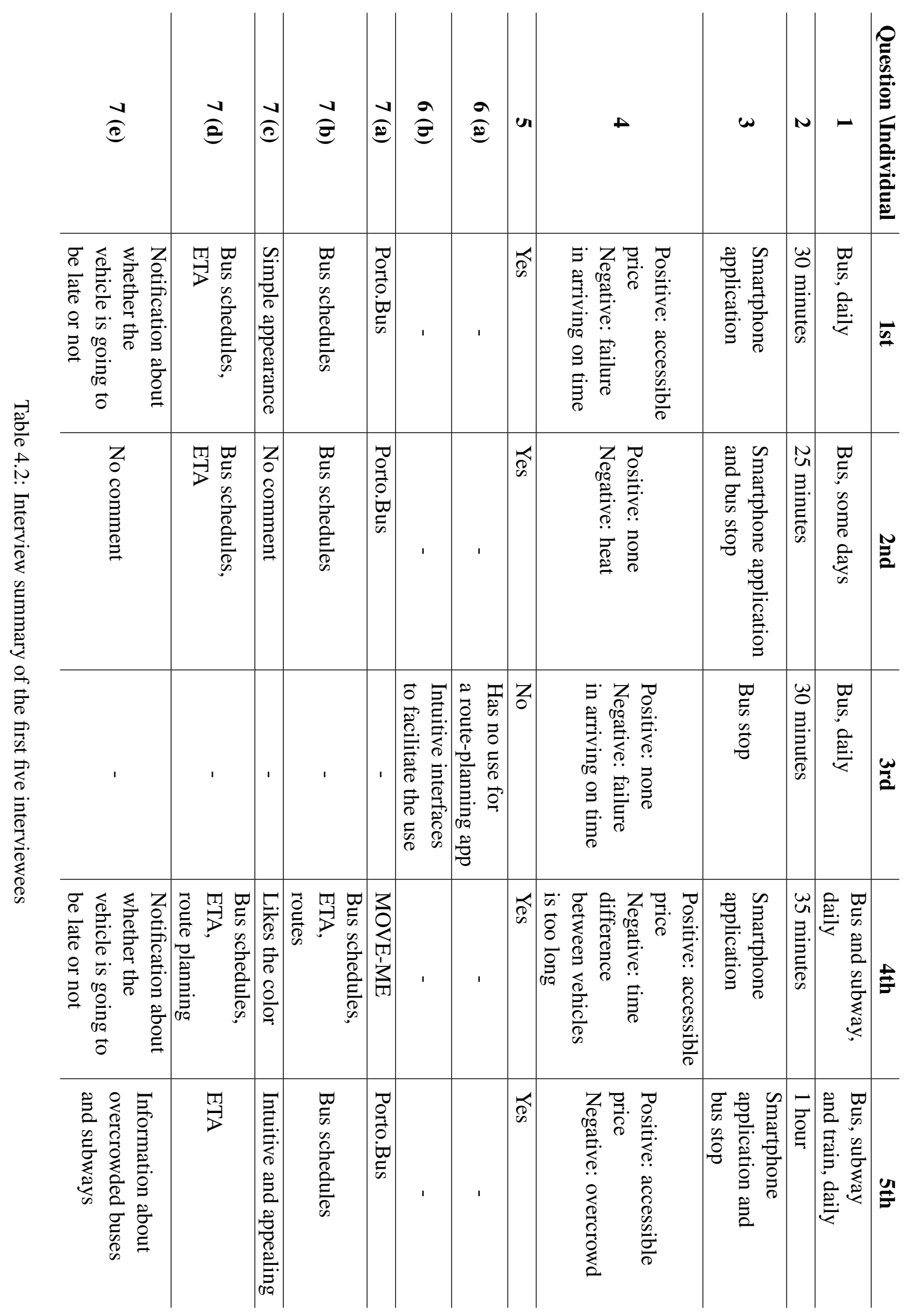




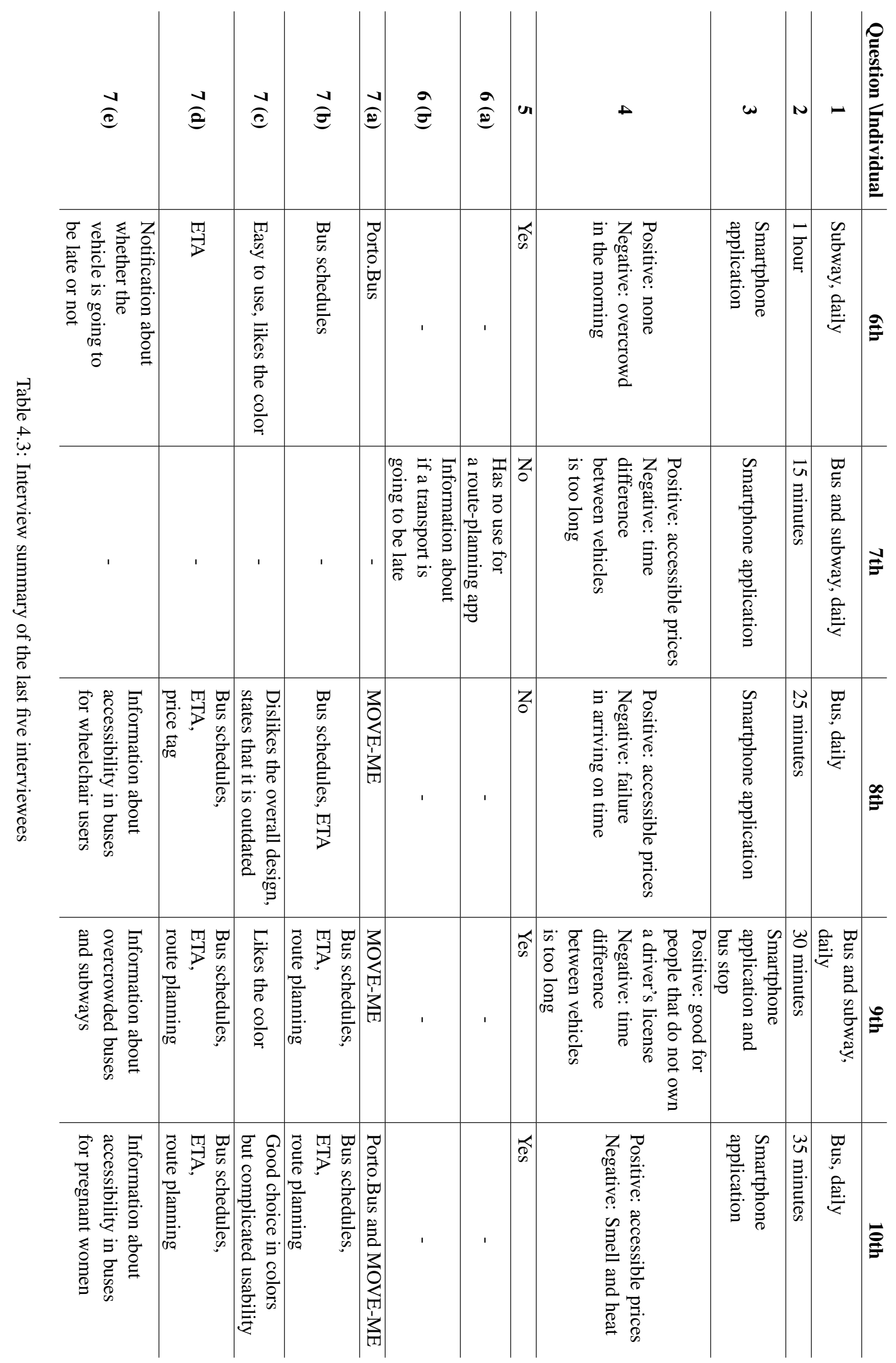


Most people stated that using the application MOVE-ME to create a route towards the pretended destination would be the best method and, especially on holiday, it is important to use an app to check the schedule of the public transports since it changes. However, two persons said that they would rather check the time of arrival of the transport in the station or stop signs, and additionally, they claimed that they did not mind waiting for the vehicle. The reason behind this sits on the fact that these people acknowledge that creating routes is too troublesome.

While interviewing, it was noticed that people had some sort of difficulty in expressing their thoughts, particularly about what new information they would like to receive and which features could eventually be implemented in the app to promote a better overall experience, and when this happened, they were proposed with examples of information based on previous research that the current apps do not have, such as information about malfunctions in the vehicles and equipment, overcrowded transports, crosswalks near each stop and station, pinpointing ramps and elevators with the hypothesis of them having to use a wheelchair or a baby carriage, and detailed information about their location and how to reach a destination. The results were extremely positive, all ten interviewees viewed this type of information as very welcoming and were quite surprise in how they were not added to the current apps yet, specifically information as overcrowded transports, malfunctions, and pinpointing ramps and elevators near and inside stop and stations.

Usually, a route planning app is vital when a traveller does not know the optimal path to take to reach a destination. Nonetheless, two out of the five first interviewees knew what transports they had to catch in order to reach the destination, which was mostly work or home. These people used an application named Porto.Bus, which mainly provides a visualization of bus schedules without real time feature. With this, they could know the ETA (estimated time of arrival) of the bus and, if that specific bus disappeared from the interface, it meant that it would not be arriving.

In Table 4.2 it is possible to see that only one of five individuals did not feel the need to use an application to help either create a route or check schedules. These interviews brought good insight on what people consider useful and useless information in a route planner, and with the scenarios mentioned before, they were able to develop and structure the response slightly better. It is clear that people consider the ticket price of public transports as the most positive factor, but in general, the interviewees thought that having the price tag of the trip within the interface wouldn't be a very important feature given the reason that a lot of people own a 40 euros pass nowadays, which gives them the advantage of not having to worry about how much the trip costs since they can travel anywhere around a certain city.

In Table 4.3 are shown the answers of the last five interviewees, which were quite similar to the first five. It can be perceived that people use the application mostly to gain information about ETA, bus schedules and sometimes route planning. When it comes to what new information they are searching for, they want to be notified mostly about whether the bus is going to miss or not and whether the vehicle is overcrowded or not; however, information about the accessibility of the vehicle and stops/stations was also mentioned, which goes into accord on what we're trying to build with this work.

The applications Porto.Bus and MOVE-ME were the two most prominent applications in the 
answers, the first one is an extremely simple app that, as stated above, allows the user to visualize the ETA of a bus in a certain stop with no real-time feature, the second one is already mentioned in chapter 2, people use it primarily to obtain information about the ETA of a vehicle, whether bus or a train.

The Figure 4.1 demonstrates the interface that appears when the user is checking the ETA of the next buses that will pass in a certain bus stop. This feature is useful although it requires that the user knows exactly which bus he or she needs to catch, so the app does provide decent information but it is not enough for a traveller that has no idea about the route of the buses.

\begin{tabular}{llll}
\hline & HSJ12 & & \\
$\mathbf{2 0 5}$ & C. Queijo & $\mathbf{5}^{\prime \prime}$ & $15: 35$ \\
$\mathbf{6 0 3}$ & Marquês & $\mathbf{9 "}^{\prime \prime}$ & $15: 39$ \\
$\mathbf{2 0 5}$ & C. Queijo & $\mathbf{1 7 "}$ & $15: 46$ \\
$\mathbf{3 0 1}$ & Hospital São João (circunvalação) & $\mathbf{1 7 "}$ & $15: 46$
\end{tabular}

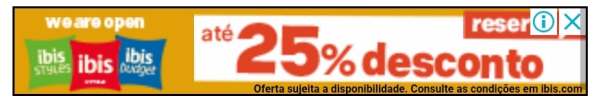

Figure 4.1: Porto.Bus interface when seeing the ETA of buses in a bus stop.

\subsubsection{Inquiry}

The inquiry counted with 30 participants, the graphic in Figure 4.2 shows the amount of people in each age range. It is important to mention that the inquiry was not spread randomly. We contacted various non-profit associations; however, the prominent one was Associação Salvador (https://www.associacaosalvador.com/), which is an association that helps mobility 
reduced people by creating various projects with the finality of promoting social inclusion. This association divulged the inquiry to their facebook followers and to some disabled people.

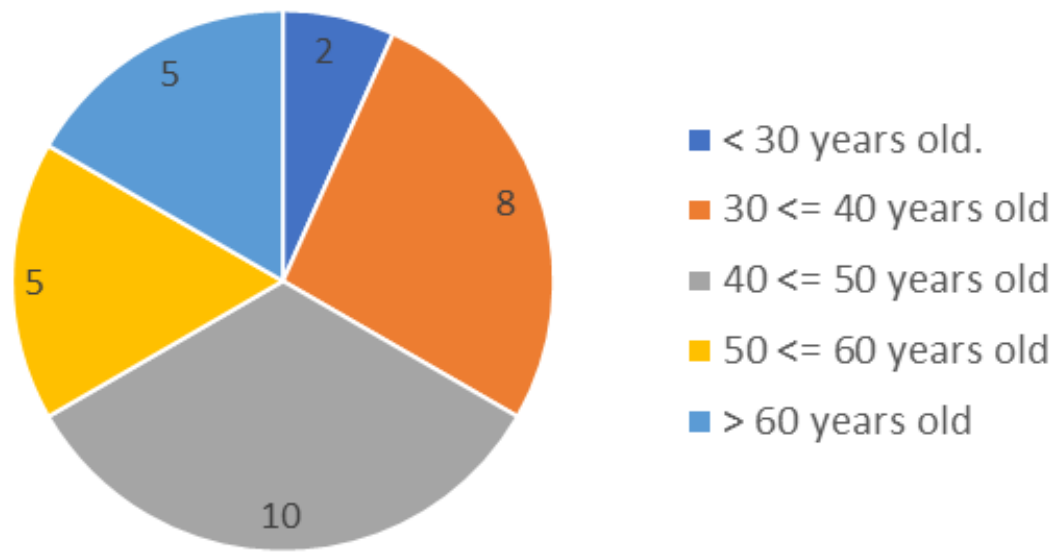

Figure 4.2: Age ranges of inquiry participants

The results of the inquiry were satisfactory, many of the answers in section three and four back up what was stated in the initial proposal, for instance, some people mentioned that it would be important for future journey planners to include information about transports that accommodate the right equipment for people with disabilities or not, and also, notifications about whether the automatic staircase and elevators situated in different stations are working or not.

In Figure 4.3 we can see the amount of people who participated on the inquiry that have physical, sensory or cognitive deficiency. $36,7 \%$ of the individuals who answered the inquiry bore any of those deficiencies, it is a decent number to consider and extract information from. Additionally, some of other interviewees stated to have family members with deficiency.

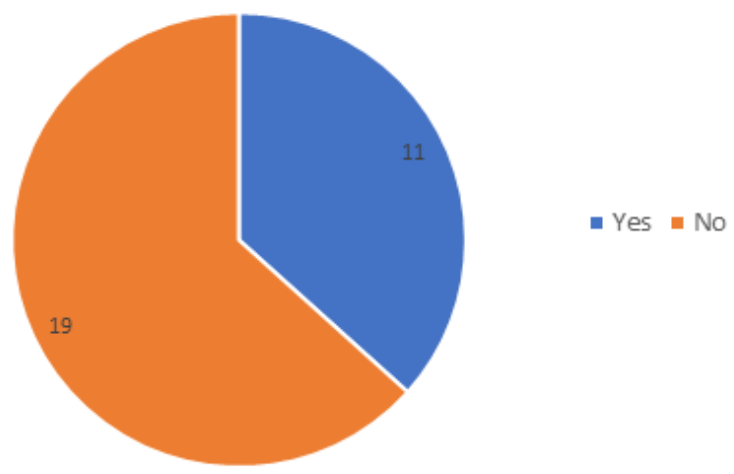

Figure 4.3: Number of people with and without deficiencies who answered the inquiry

It was also possible to conclude that 50\% (15) of people average between 10 to 30 minutes per 
trip, 40\% (12) average between 30 minutes to 1 hour, and 1 and 2 persons average less than 10 minutes and higher than 1 hour, respectively. Also, we managed to determine that most people, namely 11 people for both cases, either use the bus stop signs or smartphone applications to obtain information about public transport schedules. The chart can be seen below in Figure 4.4.

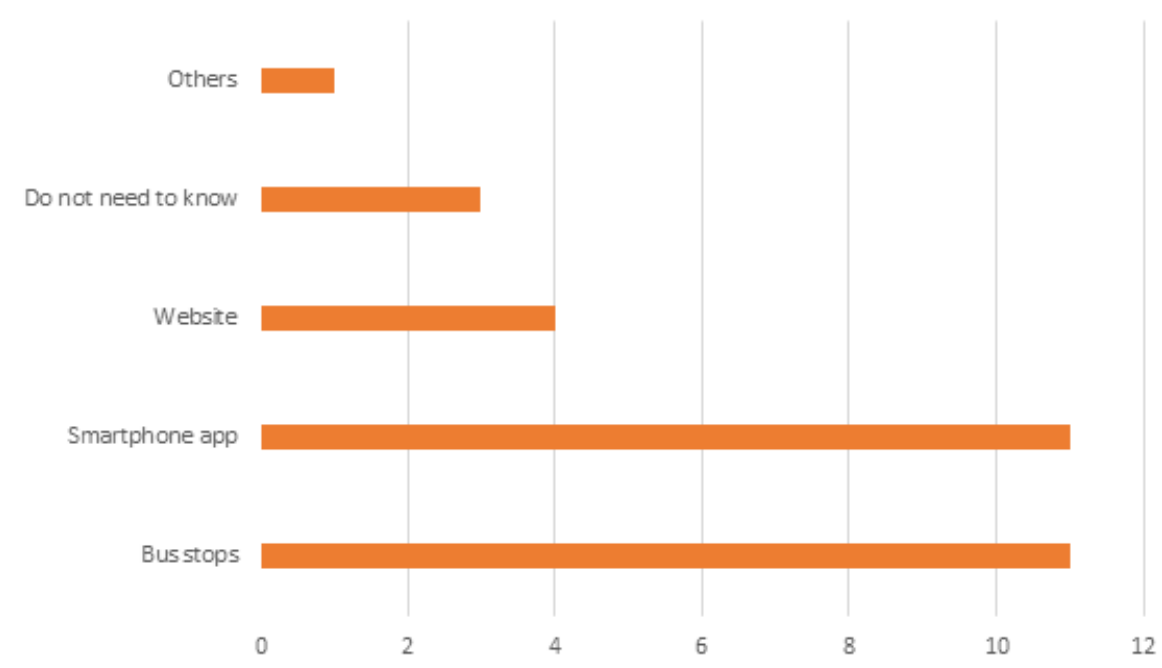

Figure 4.4: How people gather information about the schedules

Considering the reasons why 19 out of 30 people do not use any app to check schedules or plan routes, the answers vary most of the people just do not feel the need to, some use the website of the transport company, some have their private vehicle, others simply do not believe in the information provided by the applications, and a few think that the apps do not inform people about the accessibility of the vehicles and so they have no use for it (and they are right). This last group is the focus of this work, people that need to know how accessible vehicles, stations and routes are can be helped if, in the future, a software develops from the mock-up interfaces created by this work.

As for features that people who do not use apps consider important, the answers are also distinct, but it is clear that people's opinions converge, and they seek an intuitive and truthful application, which needs to be able to:

- define in real-time the ETA's of vehicles;

- state information about routes and schedules;

- maintain coherent schedules depending on traffic;

- and alerts/notifications in case of traffic suspension, route or schedule changes and the indication of the existence or nonexistence of accessibility for wheelchair users or baby carriages.

This is valuable information for the development of the mock-ups, knowing what information people consider critical is exactly what we were looking for with this inquiry. 
The information that is the most significant in these kind of apps according to actual users is public transport schedules, routes, delays and ETA. We can see the numbers in Figure 4.5. People seem to consider that prices are not a valuable information to obtain, and this was already stated before, many people own a pass which frees them of having to worry about buying tickets; however, a future application should integrate an online payment method. For that reason this feature will be given thought when designing the mock-up interfaces.

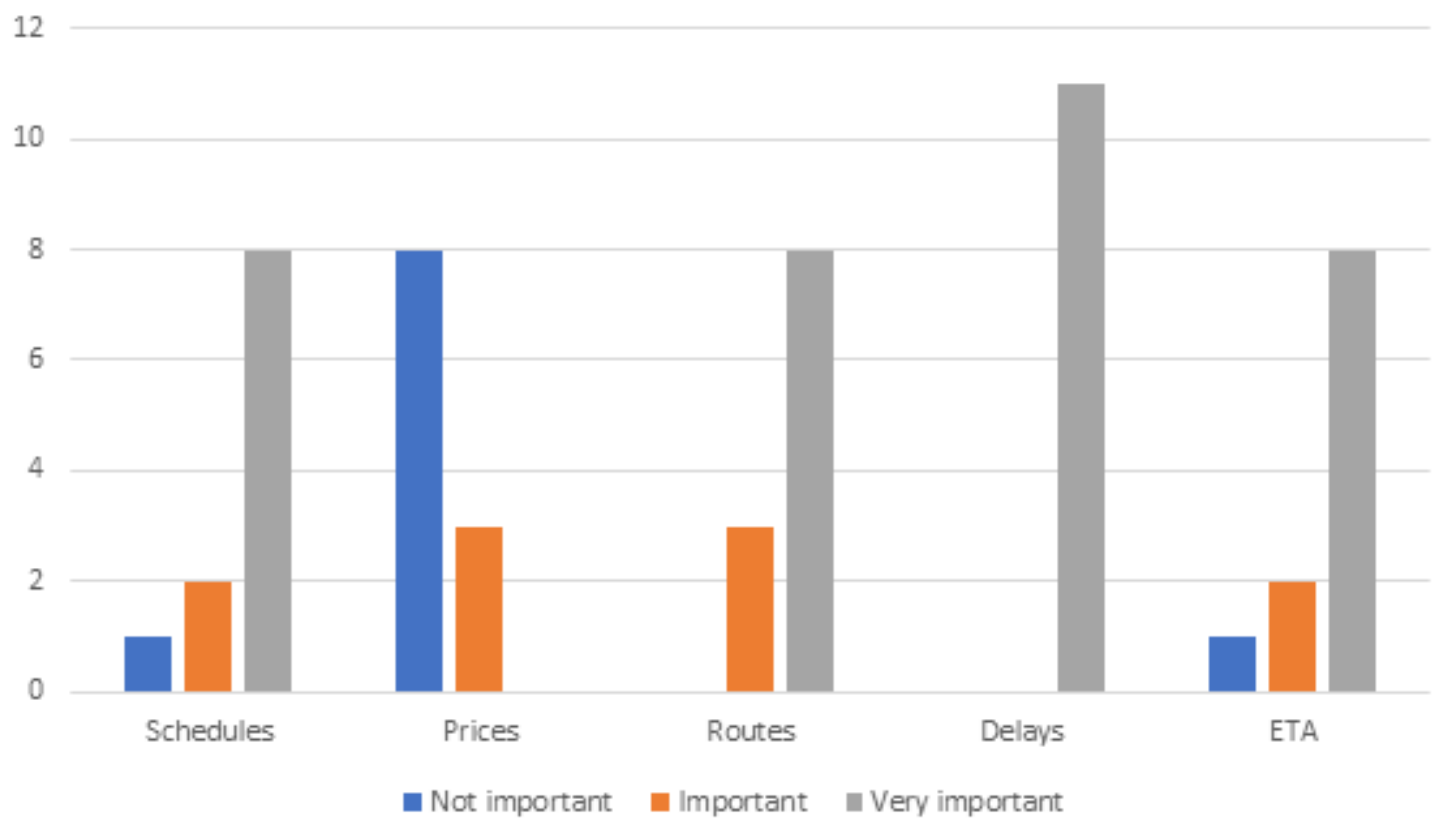

Figure 4.5: Differences of importance between information according to the users

The last four open answers were pivotal for this work, and luckily we managed to acquire good data. Many people referred that public transport apps nowadays are directed to a bigger market and marginalize mobility reduced groups by not considering certain information that is crucial for them. Lack of information about the localization of elevators and ramps near stops, places with pavement in a proper state and accessibility of vehicles was mentioned and emphasized. Once more, this converges exactly into what this work is about; therefore the requirements that were initially proposed can be considered validated and will be taken into account when developing the mock-up interfaces. 


\section{Chapter 5}

\section{Interfaces development}

This chapter will cover in detail the features that the mock-up interfaces own, mainly the ones that disclose particular information to the user. The types of information that are considered required for these interfaces were collected by reviewing the literature, interviews and an inquiry that can be accessed in chapter 4 .

\subsection{Tools}

In this work, the application of choice to create the mock-up interfaces is named Figma. This app is a web app, which means it is possible to run it in a browser and therefore on most operating systems. Figma provides all the tools needed for the design phase of a project, including vector tools which are capable of fully-fledged illustration, as well as prototyping capabilities and code generation for hand-off (Kezz, 2018). Figma also promotes team collaboration. Since it is browser-based, teams can collaborate as they would in Google Docs.

\subsection{Interfaces elements and concepts}

This work has the principle of developing simple and intuitive interfaces of an inclusive intermodal of an inclusive inter-modal application. These interfaces are mainly focused on providing a high level usability (see section 3.5) and valuable information. Most of the words are in bold and have a considerable font size (ranging from 12 to 18, being 12 the minimum for dyslexic and visually impaired readers (Evett and Brown, 2005), the size of the icons is also quite large for easy recognition. It is worth noting that the majority of the text has the color black, making a contrast with the white background, promoting a better reading experience (Evett and Brown, 2005).

The main color of the interfaces is red, for no particular reason, but a feature where the user is able to change it to a more preferable one is considered in this work. The interfaces that were developed are based on previously designed applications such as MOVE-ME, Moovit, Citymapper and Google Maps. As stated before, this work aims to mostly focus in what information is 
important to socially excluded groups, namely the elderly and the disabled, and how to share that information to those groups.

The sections that follow will explain the creation of each interface and its purpose. There are five different groups of interfaces: the main interface; subway interfaces; bus interfaces; route planner interfaces; and menu/notifications interface. There will also be a table with all the main elements integrated in the interfaces.

\subsubsection{Elements}

In Table 5.1 we can find the terminology for the main elements that the interfaces will bear. All of symbols are intuitive and therefore easily understood.

\begin{tabular}{|c|c|}
\hline Symbol & Terminology \\
\hline (5) & Accessible space \\
\hline & Overcrowd \\
\hline & Low population \\
\hline & Crosswalk \\
\hline & Traffic light signal \\
\hline & Sound signal \\
\hline & Bus stop \\
\hline & Subway stop \\
\hline & Walk \\
\hline & Destination \\
\hline ()) & Audio speaker \\
\hline$\dot{\phi i n}$ & Elevator \\
\hline & Warning/report situation \\
\hline & Turn left \\
\hline & Turn right \\
\hline W & Favourite \\
\hline$\Delta$ & Ramp \\
\hline
\end{tabular}

Table 5.1: Main elements terminology 


\subsubsection{Concepts}

\subsubsection{Main interface}

The design of the main page does not bring any information regarding the requirements that were proposed in the last chapter; however, an application needs a main page. For that reason we decided to create a simplistic one, having the words and icons to help with the navigation. This interface can be fully seen in Figure 5.1. The round icon on the left in Figure 5.2 is a button that directs the user to the subway lines of Porto interface; the right icon is also a button and directs the user to the bus operators interface, the title above states "Lines and schedules".

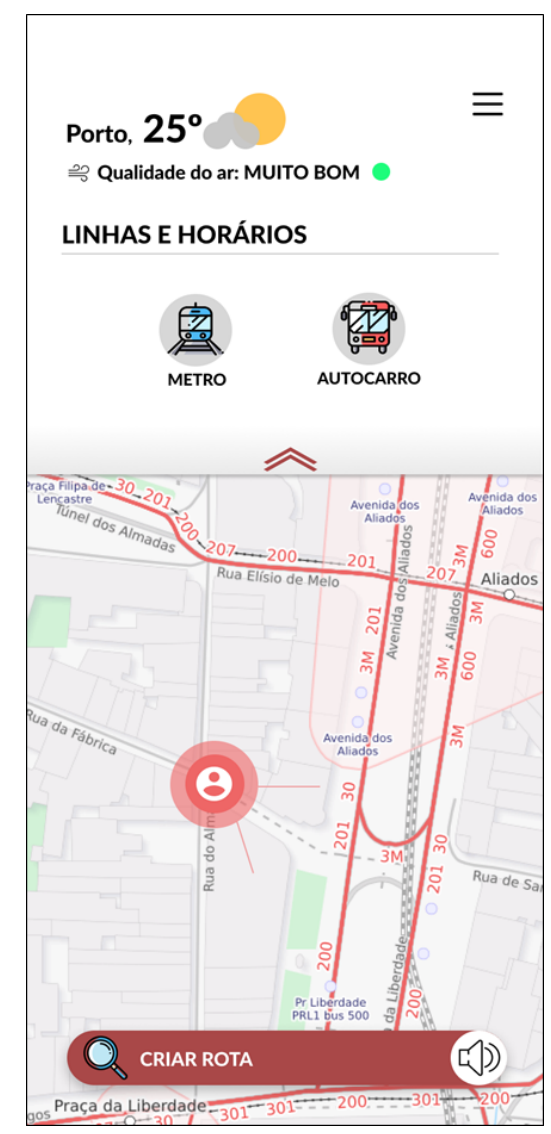

Figure 5.1: Main page interface

LINHAS E HORÁRIOS

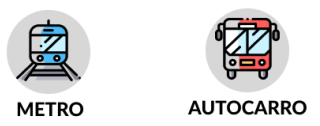

Figure 5.2: Main page - subway and bus buttons

It was decided that the weather conditions (i.e. temperature, cloud cover) and the location would consist of a good feature to implement in the interface. All public transport travellers are 
dependant on the weather to choose what clothes to dress, and it is also a good information to obtain specially if the user is an elder or a person with reduced mobility, since the weather influences the pavement. Furthermore, the elderly group must avoid extreme meteorologic conditions at all cost, and that supports the implementation of the weather condition in this interface.

Another feature that this interface integrates has not been witnessed in any route planning apps thus far, which is informing the user about the air quality, this has a big impact in human beings. The scale various from Bad to Very Good (see https: / qualar.apambiente.pt/ dashboard/observado/mapa/hoje), it is represented by a colorimetric scale composed five colors, namely: red, orange, yellow, green and light green, ranging from Bad quality to Very Good quality respectively. In the example, under the weather conditions, it is possible to see that the air in Porto is Very Good.

In Figure 5.3 it is represented the lower button of the main interface, which directs the user to the route planning feature. If the interface was part of a real application, the user would be able to pick the destination from a starting point. Notice the speaker icon on the left, this icon appears in every interface and it represents a feature that would be able read what was written inside the button, in this case it is "criar rota" which stands for "create a route". This feature was considered due to the existence of people with impaired visualization and dyslexia.

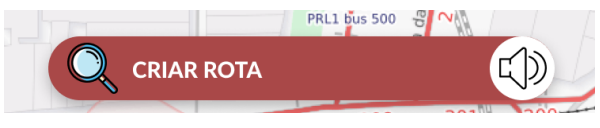

Figure 5.3: Main page - route planning button

The last button on this interface is the three bar square on the top right (Figure 5.13), which represents a menu button, when pressed, the menu interface comes up and brings out four more buttons, but only two of them have an interface, since the others are not as important. The menu interface will be covered later in this chapter.

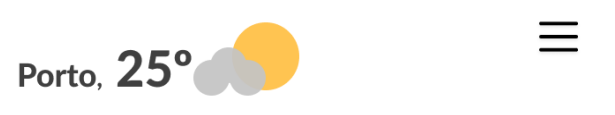

Figure 5.4: Main page - menu button

\subsubsection{Subway interfaces}

Figure 5.5 (a) is the first interface that shows up after clicking on the subway button in the main screen. It is meant to represent all the subway lines of Porto in an intuitive manner. 


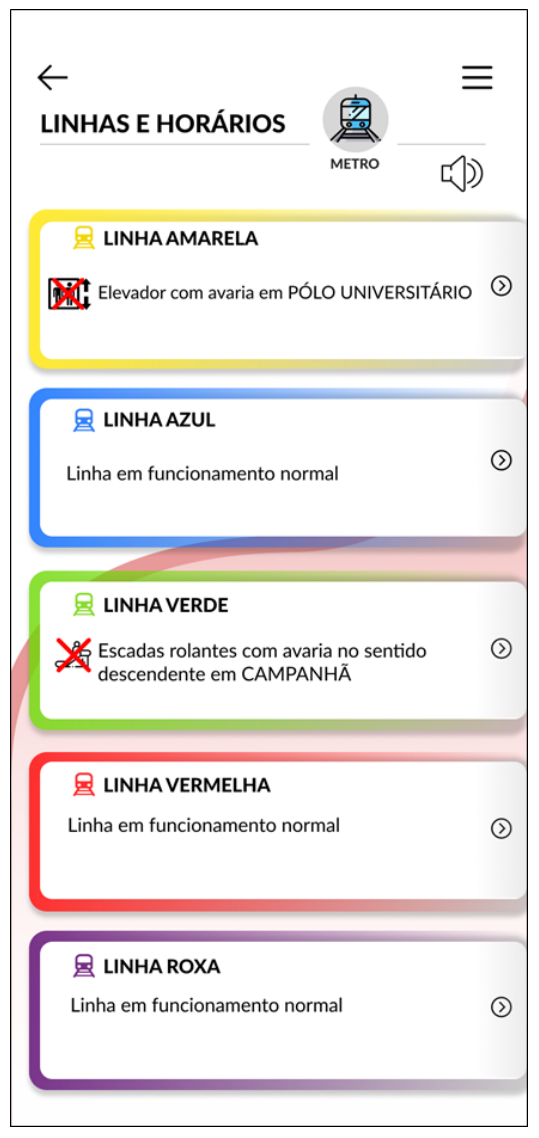

(a) 1st subway interface - subway lines

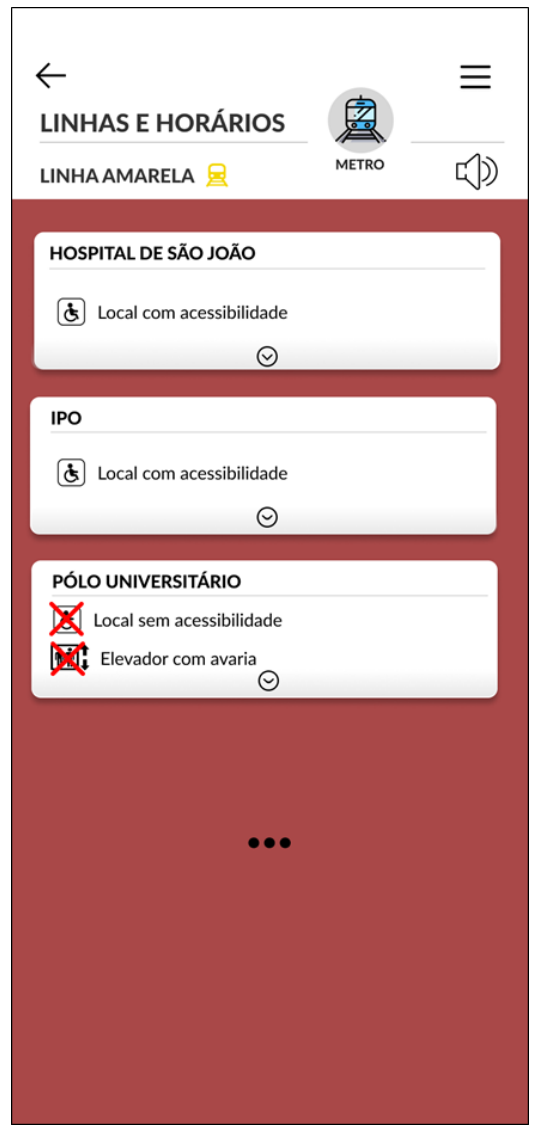

(b) 2nd subway interface - yellow line stations

Figure 5.5: Subway lines interfaces (Part 1)

Each subway line is represented by a color, so that same color was aggregated around the respective line in order to be easily perceived by people with cognitive and visual problems. This interface informs the user about certain events that might happen in each line, for instance, in Figure 5.5 (a), it is possible to see that the yellow line has a problem in the elevator in the station PÓLO UNIVERSITÁRIO, and the green line has a malfunction on the automatic staircase located in CAMPANH $\tilde{A}$, information that is extremely important to people that lack mobility.

This information goes into accord to what was stated on the pavement requirement in 4. Letting people know if everything is working smoothly or not is needed and should be considered in future software development for route planners.

In Figure 5.5 (b) we can see an example of what happens if we click the yellow line. The second subway interface pops up and is composed of all stations/stops that the yellow line owns, but to facilitate perception, only three of sixteen stations were exemplified since it is possible to generalize to the other stations accordingly. The main objective of this interface is to provide information about whether the station is accessible to wheelchair users or not, if the elevators or the automatic staircases are working properly and if the line is working or stale. As we can see 
in the example, the elevator has a malfunction in PÓLO UNIVERSITÁRIO, the same information that was disclosed in the previous interface Figure 5.5 (a)).

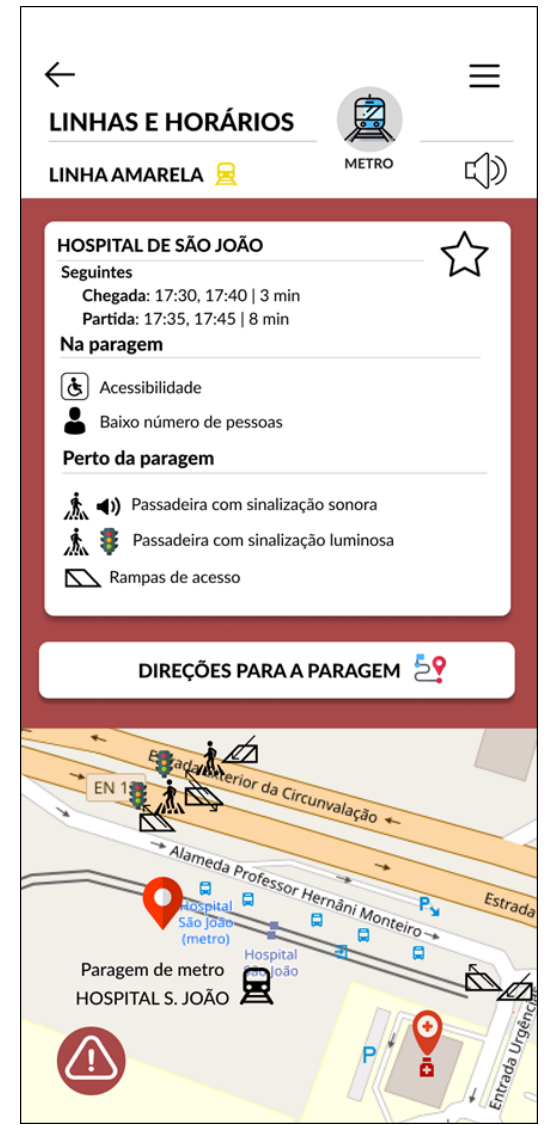

(a) 3rd subway interface - station information

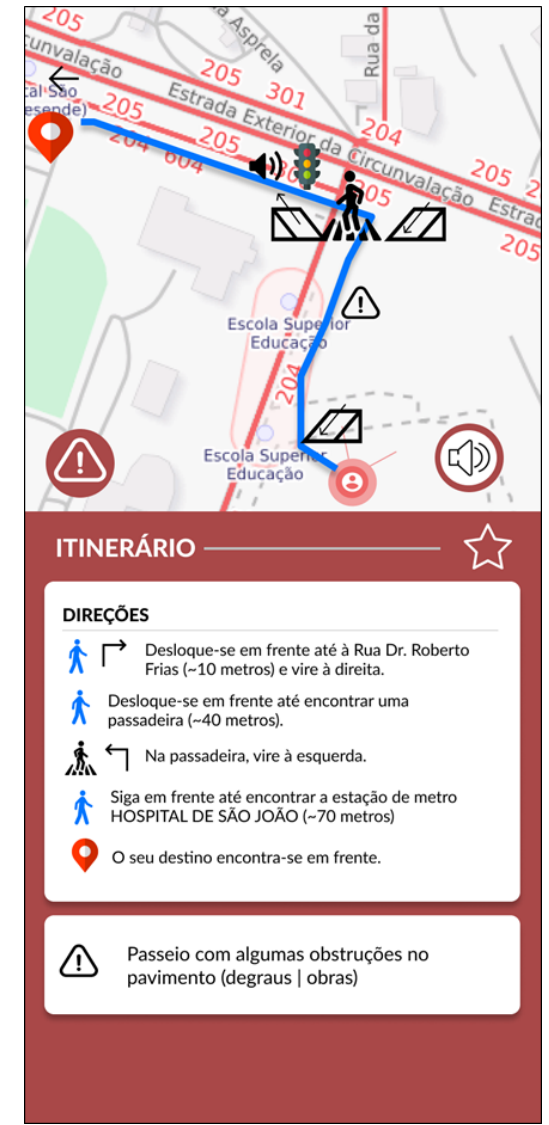

(b) 4th subway interface - route creation

Figure 5.6: Subway lines interfaces (Part 2)

The user is then able to select a station in order to obtain more information about it. The example in Figure 5.6 dictates that the user pressed HOSPITAL DE SÃO JOÃO STATION, and it is now possible to see a wide range of information such as: the next arrival and departure of the transport; if the station has accessibility for wheelchair users or not; if the vehicle is/will be overcrowded; if there are crosswalks near the station with integrated sound and light signs; and if ramps are nearby. The interface also incorporates a mini map which allows the user to recon the station premises so that it facilitates the location around and even inside it.

In the middle of the screen, in Figure 5.6 (a), there is a button that states "Direções para a paragem" which translates to "directions to the station"; when pressed, it directs the user to the interface on the right (Figure 5.6 (b)). This interface has the goal of instantly creating a routeplanner, having as the destination point the station, and as the starting point the place where the user is currently located.

In the example, the user is at Escola Superior de Educação, and a map as well as directions 
appear on the screen. These directions lead the user to it is destination, but the important information in this interface are the icons on the map. These icons can represent either ramps, elevators, crosswalks with sound and light signs, automatic staircases, physical barriers, steps, steeps and other overall obstruction information that might contribute to the user's knowledge. In this case, the route is composed of three ramps and a crosswalk with light and sound signs. In addition, we can see underneath the directions tab a warning sign with a message, stating that the pavement has obstructions such as steps and construction. Once again, this information would be important for a traveler with low mobility. The directions are also clear and incorporate icons to facilitate understanding.

\subsubsection{Bus interfaces}

The bus interfaces that were developed bear the same kind of information as the subway interfaces as they disclose information about bus schedules, obstruction within the bus stop or nearby and vehicle accessibility. Additionally, the interfaces share data about whether the transport is overcrowded or not, and there is also the feature where a user is able to create a route towards the stop, depending on where the he or she is located. Figure 5.7 represent the first two bus interfaces.

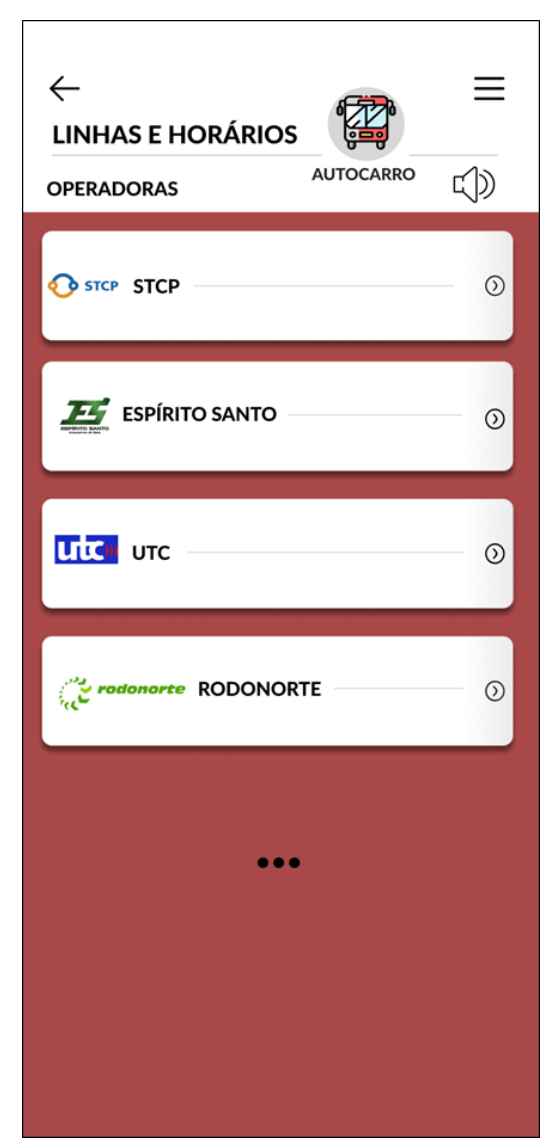

(a) 1 st bus interface - operators

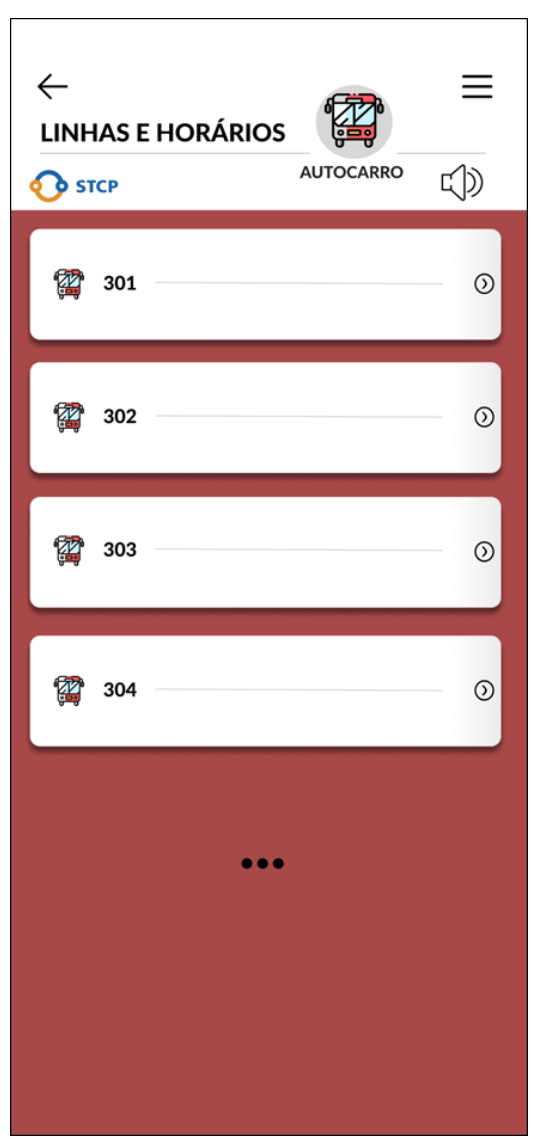

(b) 2nd subway interface - buses

Figure 5.7: Bus interfaces (Part 1) 
After clicking in the bus icon on the main page, the user is redirected to the bus operators interface (Figure 5.7 (a)). After clicking the desired operator (in this case it is STCP), Figure 5.7 (b) comes up, allowing the user to choose which bus he/she wants to know information about. These two interfaces have no particular information oriented towards mobility reduced people, once they simply act as a middle link between the main page and the interfaces that come next although they are useful in filtering the information regarding which operator and bus the user wants to know about.

When the user decides which bus he requires information about (in the example it is bus number 301), he/she is then proceeded to an interface, represented in Figure 5.8, that contains the various stops that the bus passes through. Even though this interface can be considered a middle link just like the previous two, it packs a little information about whether the bus stop is accessible for wheelchair users or the opposite, and this can be seen by the icons and the statement in front. For the sake of keeping the mock-up simple and understandable, we created a route that only has four bus stops and the three dots represent that in reality, there are more stops.

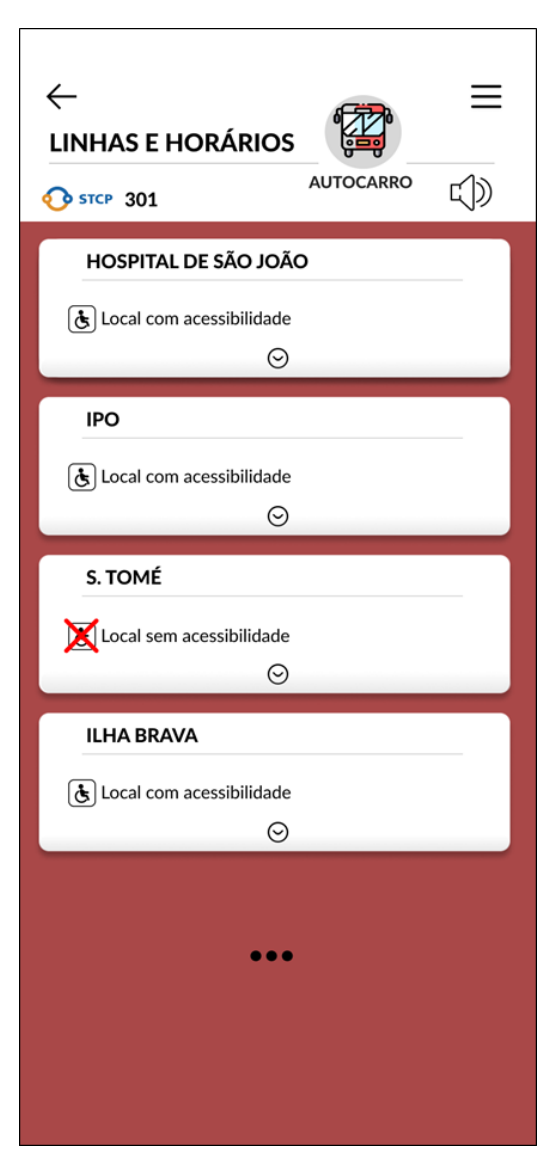

(a) 3rd bus interface - bus stops

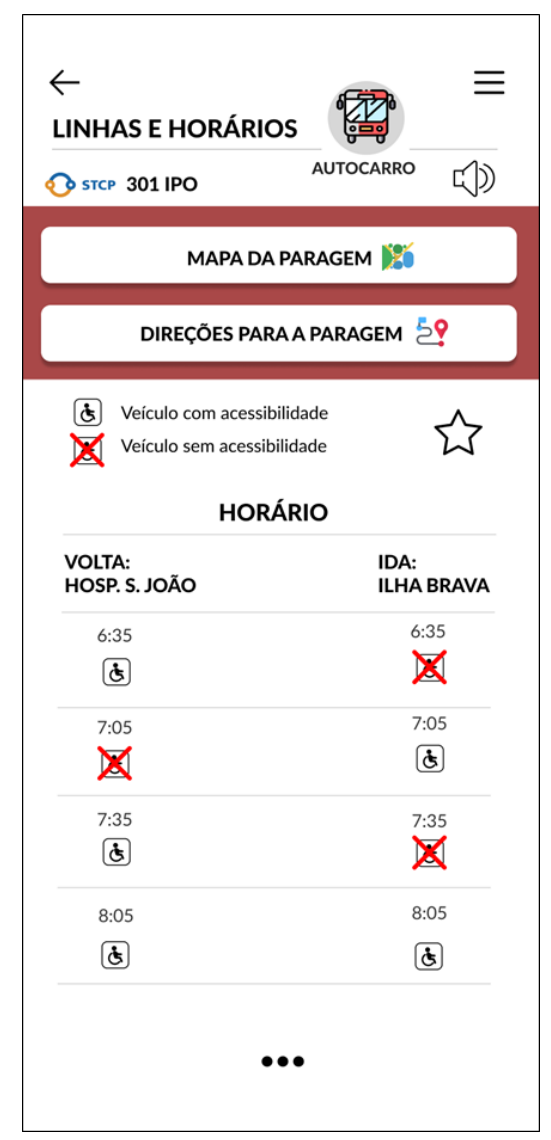

(b) 4th bus interface - bus stops information

Figure 5.8: Bus interfaces (Part 2)

The next interface, presented in Figure 5.8 (b), appears after one bus stop is picked. In this 
situation it is IPO bus stop, allowing the user to obtain information about bus schedules of bus STCP 301 in that stop, as well as the accessibility of each vehicle that belongs to those schedules. In the example we can see that the first vehicle that passes in that stop with direction towards HOSP. S. JOÃO arrives at 6:35 and is able to transport wheelchair users since the icon below the time is not crossed. With this, if the user requires a wheelchair for mobility, he/she is able to get information about whether to catch the bus or wait for a more convenient one.

there is also a couple things to point out in this interface, particularly the two buttons on the top of the screen and the star. The first two buttons redirect the user to a street map of the bus stop and to an interface that creates a route towards the stop, depending on where the user is, from top to bottom respectively. The star icon represents a favourite, i.e. if the user would like to gain information (i.e. ETAs, delays, overcrowded buses) through notifications about the STCP 301 buses that arrive on the IPO bus stop, he/she just needs to click the star. This feature is important to promote an easier time in acquiring information, and it will be explained further in this chapter. These two interfaces bear the same goal as the ones represented in Figure 5.6. Thus, the information that is provided is basically equal, so that the user knows, for example, about physical barriers that the route contains, crosswalks, and if the vehicle is overcrowded or not. These interfaces can be seen in Figure 5.9.

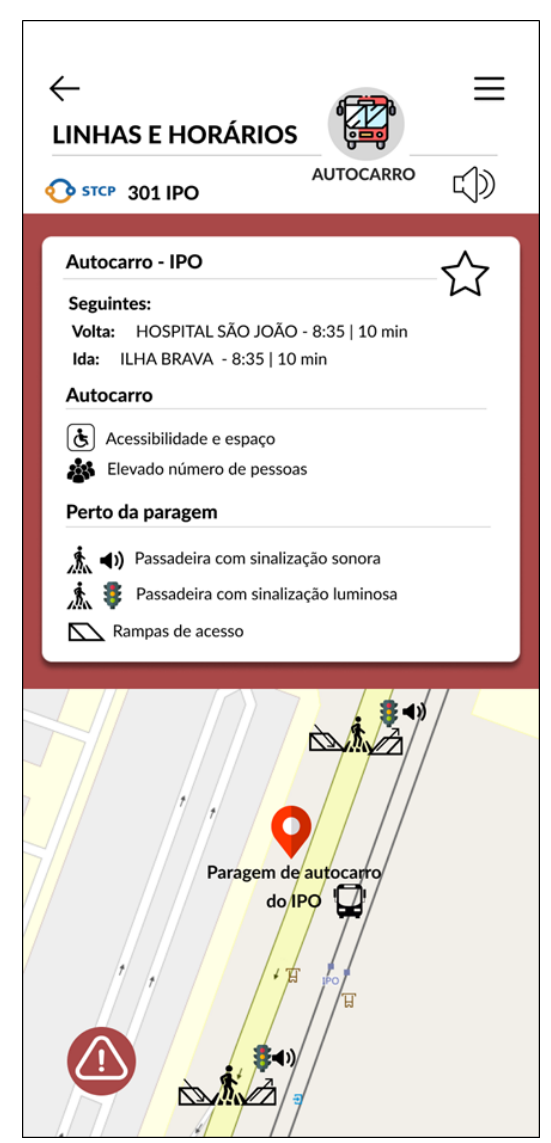

(a) 5th bus interface - bus stop map

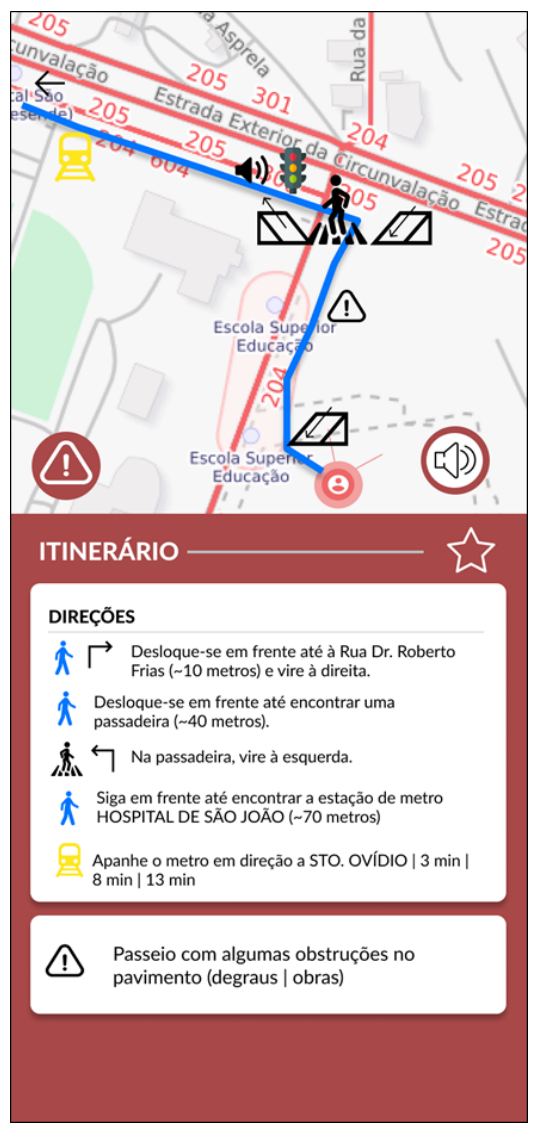

(b) 6th bus interface - route creation

Figure 5.9: Bus interfaces (Part 3) 


\subsubsection{Route planner interfaces}

When a person wants to go somewhere and does not know which transports to catch, he/she may utilize the route planning feature by clicking on the "Create Route" button, shown in Figure 5.3. The user will then encounter himself/herself in an interface that demands a destination and a starting point, like most journey planning apps in the current market.

After choosing the destination of the trip and the starting point a few possible routes arise and appear on screen, as we can see in Figure 5.10, where are displayed the two first interfaces that belong to the route planner. On the left, it is demonstrated an example of how the interface would look like if the user decided to go from HOSPITAL DE SÃO JOÃO to ALIADOS, three possible and imaginary routes appear, composed by lines with different colors, each color represents a method of transportation:

- the blue line, which represents a walking route;

- the black line, which represents a bus route;

- and the yellow line, which represents the subway route (this color could change depending on the subway line (i.e. green line, purple line, red line, etc).

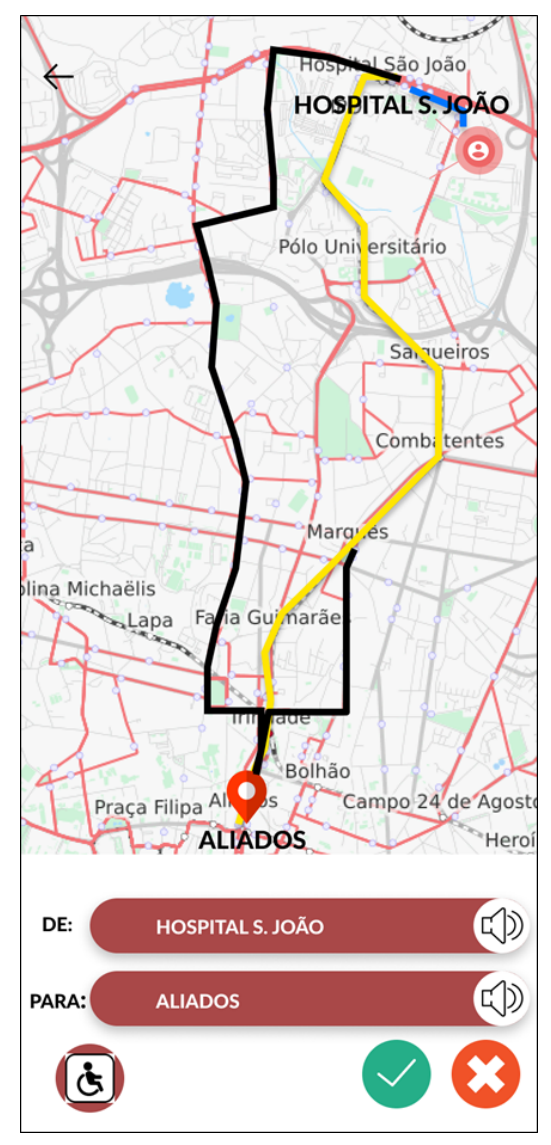

(a) 1st Route planner interface

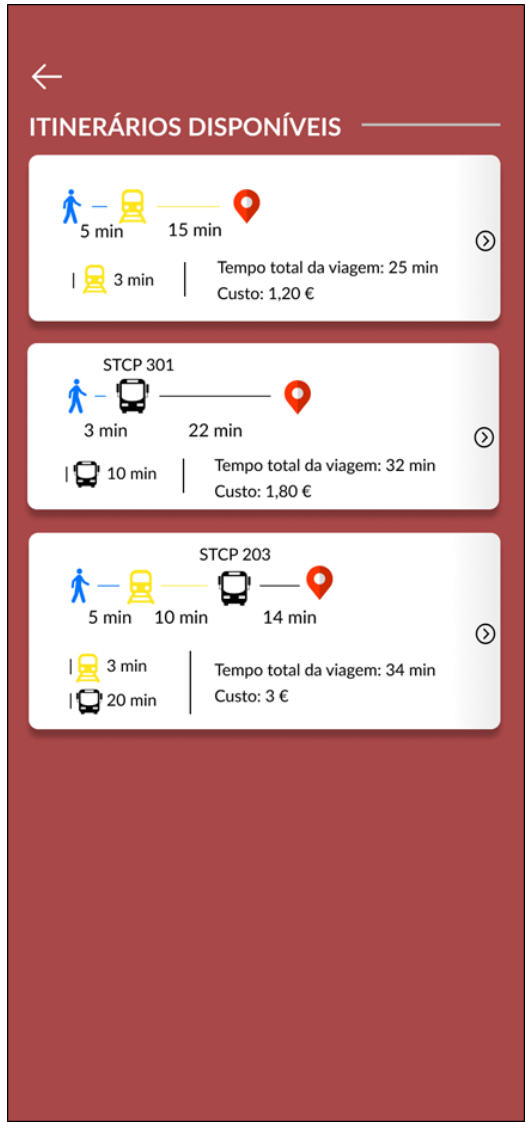

(b) 2nd Route planner interface

Figure 5.10: Route planner interfaces (Part 1) 
This interface also provides a feature that is very appealing to mobility reduced people, specifically, wheelchair users or people with baby carriages, at the bottom left corner there is a button that, when pressed, can rearrange the routes that were suggested so that the route planner only take into account vehicles and stations with proper accessibility for those people. This is a feature that has never been implemented before and seems very promising since it facilitates the search for buses or stations with accessibility.

When the user is ready, the next step is to click the check button with green background. If the user decides that none of the routes satisfy, he/she can simply cancel the action by clicking on the cancel button with red background. This will redirect the user to the main interface.

Now shifting the focus towards the interface to Figure 5.10 (b), this one integrates a considerable amount of information. It informs about the routes in the previous interface, each white box refers to a different route and the primary objective is to warn the user about:

- methods of transportation that each route requires - the icons represent each method of transport that is integrated within the route: walking, subway and bus are the ones stated in the example; these icons have the same color as the lines in the previous interface, blue, yellow and black respectively;

- total and travel time of the trip - between each icon there is a timestamp which informs the user about the time needed to reach a subway or a bus station/stop and the time of each trip in different vehicles since this is named by travel time and the line between each icon stretches accordingly. There is also the total amount of time that the trip will take that include: (i) walking time, (ii) waiting time, and (iii) travel time. This is very important as it lets the user know at what time will he/she arrive at the destination;

- trip cost - this informs the user about the price of the trip;

- estimated time of arrival - at the bottom left corner of the various routes we can see the ETA's for each vehicle.

After figuring out which route is better, the user can simply click on it and, consequently, another interface will pop up. For exemplification purposes, let us admit that the user chooses the last route, which is the longest. This interface has the goal to keep the user warned every step of the way, providing detailed directions as well as a mini map with icons concerning ramps, crosswalks and so on, being the same as Figure 5.6 (b). This interface can be seen in Figure 5.11, the two figures represent the same interface. However, the user is in different locations, since the longest route was chosen, which implies a multimodal trip, and for each station and stop there is different information.

In the left figure the user is located in Escola Superior de Educação, and the directions lead to HOSPITAL DE SÃO JOÃO subway station, stating that it is required to catch a subway towards STO. OVÍDIO. If the user manages to catch the subway, a second interface will appear, which is in Figure 5.11 on the right, and the directions dictate that the user has to leave the subway in 
MARQUÊS station. After reaching that subway station, the user must walk to the nearby elevator and to go the first floor, afterwards, he/she should walk straight reaching a crosswalk, proceed to cross it and then the bus stop is located to the right.

This interface accommodates a large amount of information, which is somewhat concerning as it might provoke confusion to people with cognitive problems. However, all the information stated is considered relevant and it is written in the a simplistic and intuitive way.

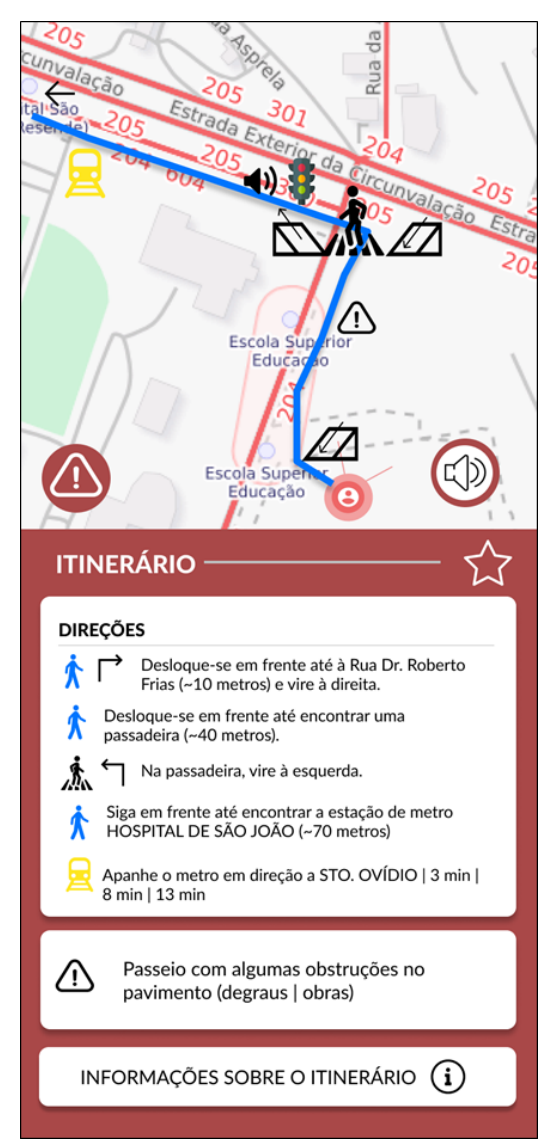

(a) 3rd Route planner interface

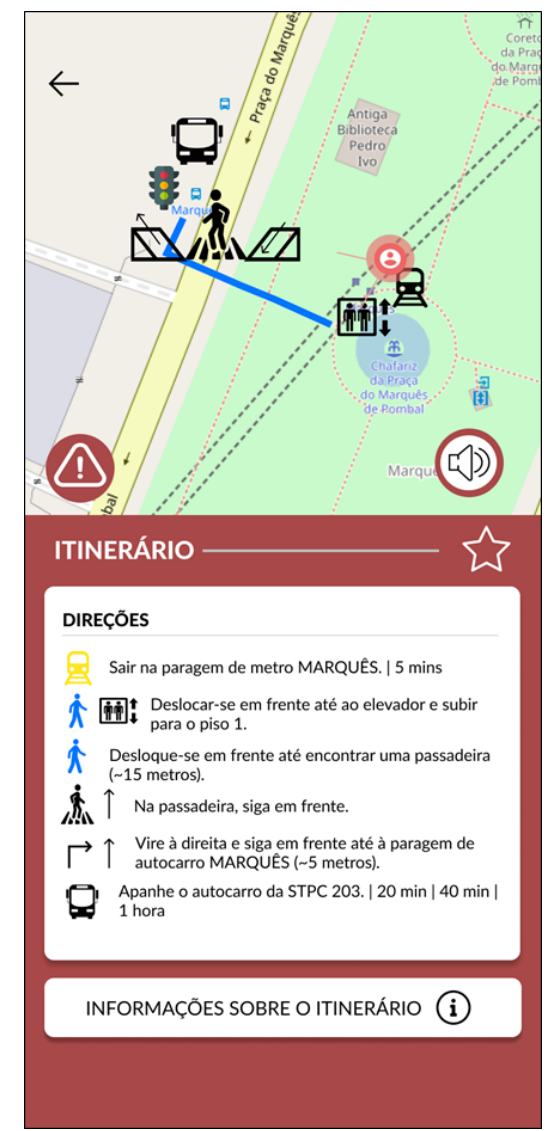

(b) 4th Route planner interface

Figure 5.11: Route planner interfaces (Part 2)

Much like the interface proposed in the last Figure 5.6, these interfaces have the goal of provide the following information:

- detailed directions to reach stations or stops;

- ramps, crosswalks, elevators, steps, or any other kind of obstruction;

- and ETA's of the transports.

A button named "INFORMAÇÕES SOBRE O ITINERÁRIO" is located at the bottom of both interfaces, redirecting the user to a new screen that provides information about each stop, and 
continuing with the example above, two stations exist in the route: HOSPITAL DE SÃO JOÃO and MARQUÊS subway and bus station respectively. The interface can be found in Figure 5.12.

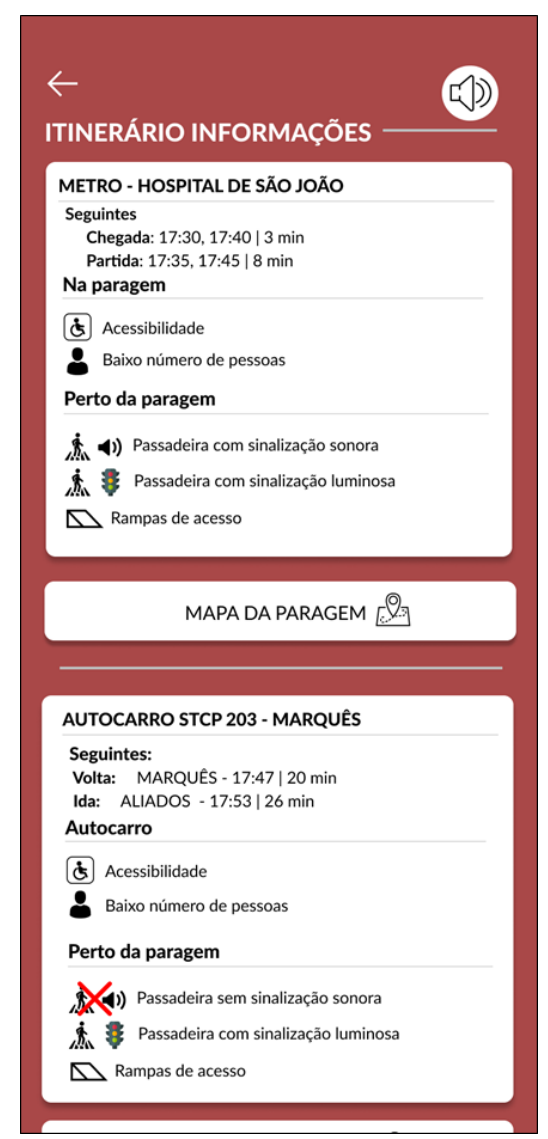

(a) 5th Route planner interface

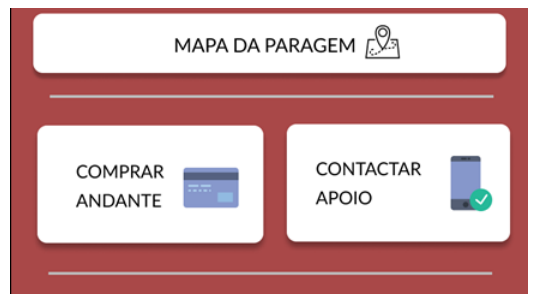

(b) 6th Route planner interface

Figure 5.12: Route planner interfaces (Part 3)

This interface provides information about the existence of ramps, crosswalks with or without light and sound signals, accessibility near the stations/stops, accessibility in buses, overcrowd vehicles and ETA's. Also, the shorter picture at the right in Figure 5.12 would be the continuation of the interface at the right when scrolled down, and three buttons appear: one button was covered before, being the map of each station and the other two buttons represent features that could be implemented in real applications, like ticket purchase as it is stated in the left button, and reach out for support to the transport operators at the right.

\subsubsection{Menu and notifications}

As it was previously stated, a menu feature was implemented in the interfaces, but this is nothing new as most journey planners contain one. Nonetheless, this menu contains five buttons, two of them received specific interfaces. The interface can be seen at the left in Figure 5.13. The menu is simplistic and promotes contrast with the white over the dark red. 
On the right in Figure 5.13 it is represented the interface of a feature that exists in certain route planners but it is not very promoted, which is the favourite feature. If a user is able to favourite a route, subway station or a bus then it would facilitate in obtaining information about those, basically because the app could provide notifications about what is going on with a certain bus, or simply inform the user that a subway is full, this type information could also range from delays to malfunctions or obstruction. If the user decides to delete a favourite, the interface also provides that feature, there is a cross button on the top left of each favourite, it is also possible to view the favourite by clicking on it.

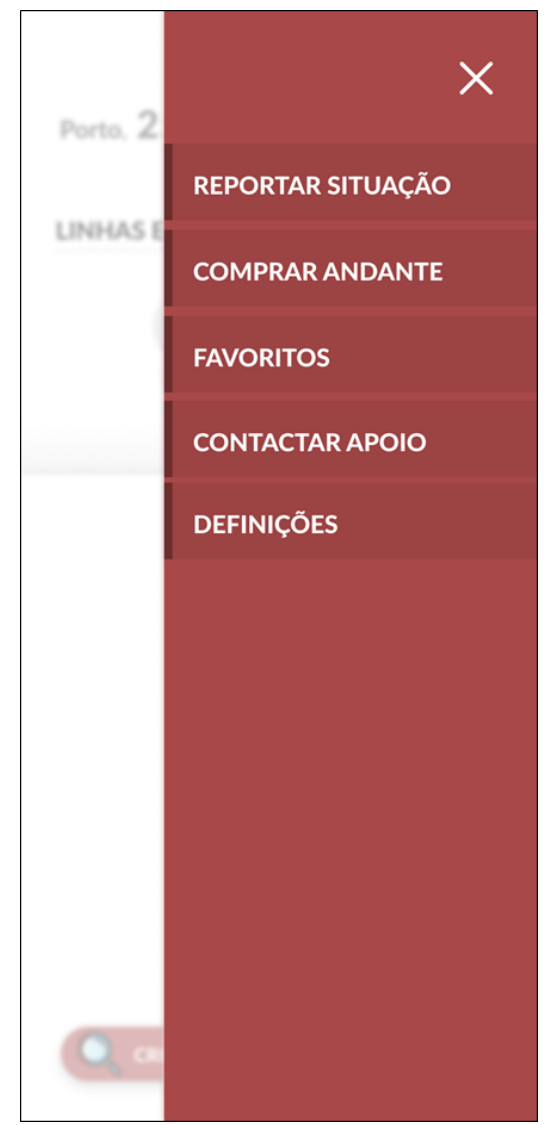

(a) Menu interface

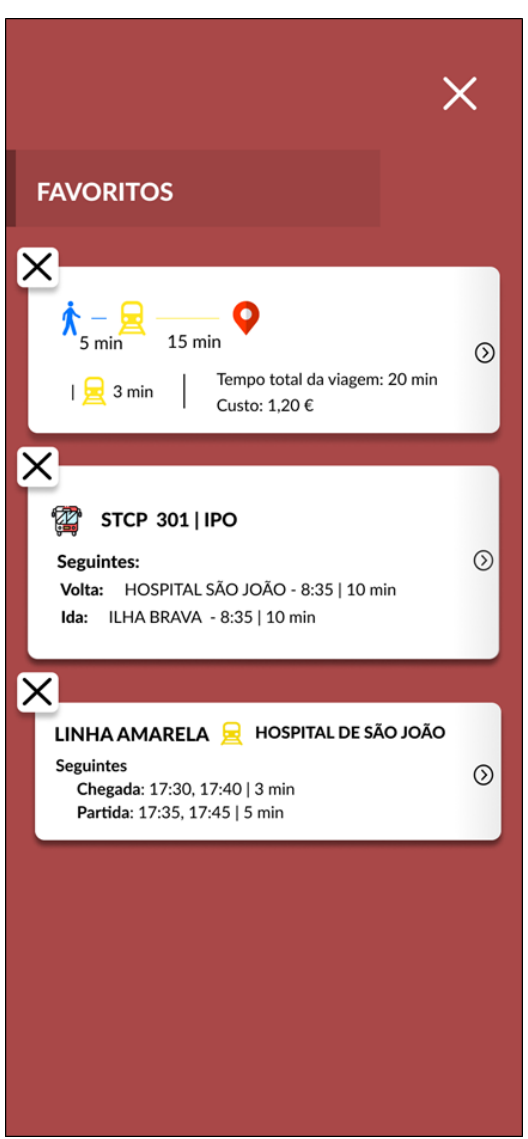

(b) Favourites interface

Figure 5.13: Menu and notifications interfaces (Part 1)

An interesting feature that it was decided to mention is based on crowdsourcing; this allows the users to provide information that they consider useful to the application, and the same will analyze and divulge with other users.

The feature is a situation report and it comes with a small inquiry, as it is possible to see on the left in Figure 5.14. Firstly the user should state the locale where the occurrence happened, secondly, the user is given a few choices to define what kind of occurrence is going on. This could vary, for instance a delay on a transport, an accident, incorrect information provided by the app, obstruction and others, the last step would be to describe as detailed as possible the situation 
such as stating the number of a vehicle or an address. Eventually a feature that allows the user to pinpoint a spot on a map could be implemented.

The notifications examples can be seen at the right of Figure 5.14, this feature would be a game changer for a route planner, it would provide solid information that the users actually care to know, mainly because they decided to save something as their favourite, this being, for instance, a bus, the app could provide information about ETA's, delays and overcrowd.

It is worth mentioning that all the interfaces contain a sign of danger embedded in a red circle that represents a button that allows the user to instantly reach the situation report interface to provide fast feedback in any kind of anomaly that might be happening.

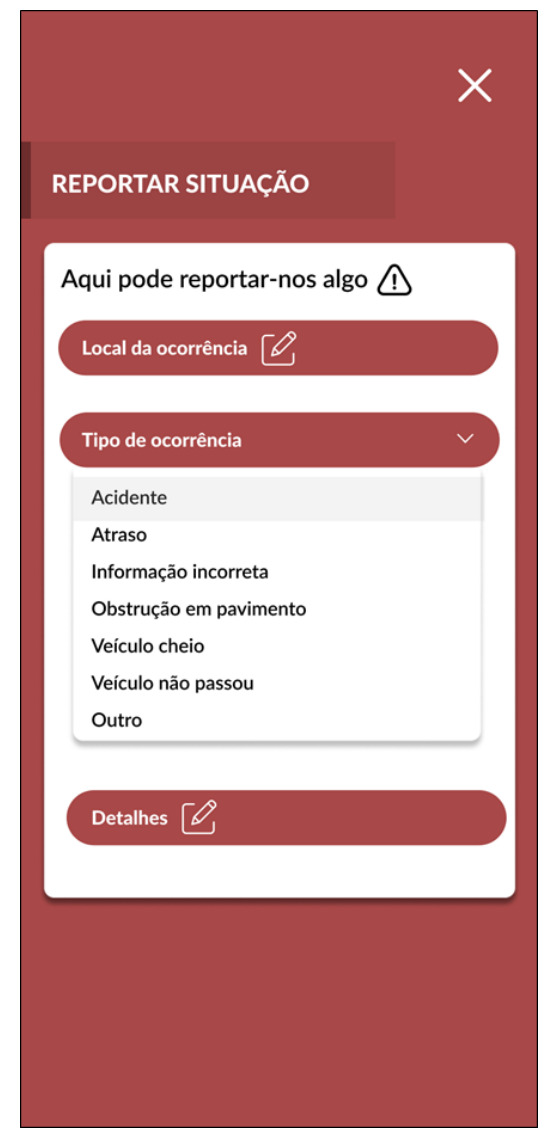

(a) Menu interface

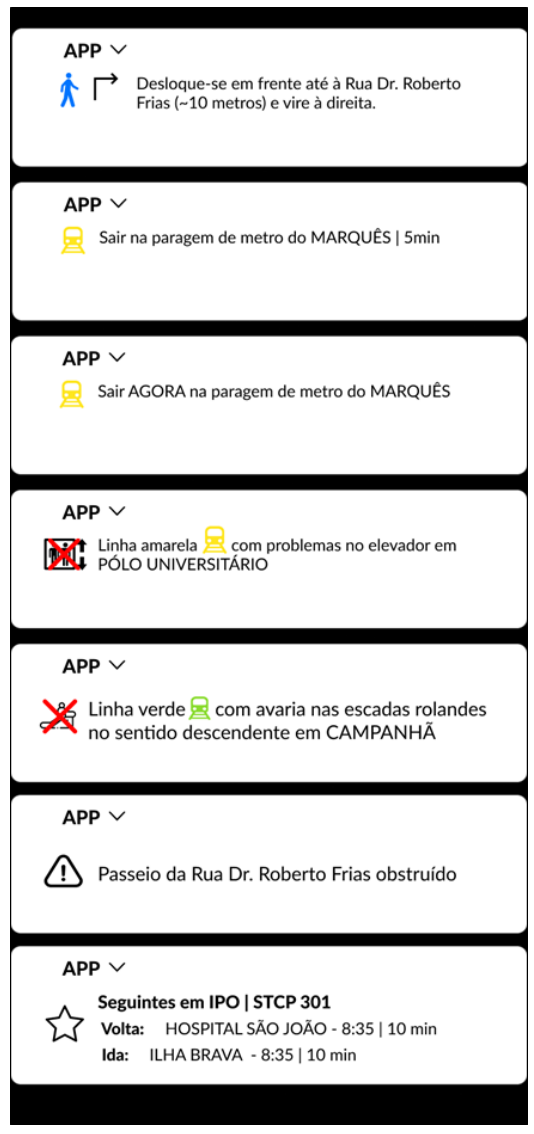

(b) Favourites interface

Figure 5.14: Menu and notifications interfaces (Part 2) 


\section{Chapter 6}

\section{Usability evaluation}

In this chapter it is presented the methodology applied to assess the usability of the user-interfaces developed, following a two-step approach: (i) an evaluation with experts in App development for providing public transport information, and (ii) an inquiry to the general population. Next sections present the methodology and results achieved with that evaluation.

\subsection{Methodology}

In this work, the effectiveness of the user interface of the low-level prototype, was assessed following the recommendations of Nielsen and Budiu (2012). In this analysis, the evaluation was conducted at two stages:

1. An evaluation session with experts in the field was conducted; and

2. An inquiry to the population was applied.

This evaluation aims to identify and understand what needs improvement regarding the interfaces, and if what has been done is viable or not. The next sections present the details of the methodology followed.

\subsubsection{Expert evaluation}

After the conclusion of the design phase, it was scheduled a session with experts in App development for providing public transport information (company OPT - Operação e Planeamento de Transportes). This was to evaluate the design that was developed. A few interfaces were not evaluated. This was due to the fact that they look very alike the ones that were previously shown.

The session was organized in three steps:

1. An introduction to what had been done;

2. A free exploration through the interfaces by the experts; and 
3. A discussion about the design and the information provided by the interfaces and additional thoughts.

Normally, mock-up interfaces are static and hard to interact with though this project was developed utilizing the Figma application, which allows the user to add an interactive feature to each interface. This means that the experts could not only evaluate the design but also the usability of the interfaces.

\subsubsection{Inquiry}

An inquiry was created in order to obtain feedback from public transport application users, and again, Associação Salvador helped spread the survey across. This inquiry contained most of the interfaces that were developed and a single choice question regarding the information within them, allowing us to understand if it was easily perceived or not.

As stated above, the inquiry that was created had the intent to understand the people's opinion regarding the information that several interfaces cover. The questions contained all the bus, subway and route planning interfaces.

A difficulty bar, as exemplified in Figure 6.1, attached to a question beforehand, was used to ask the individual to evaluate the difficulty in perceiving the information that the interface transmitted. For this purpose, the Likert scale (https://en.wikipedia.org/wiki/Likert_ scale) was used, ranging from 1 to 5 , where 1 represented very easy and 5 represented very difficult.

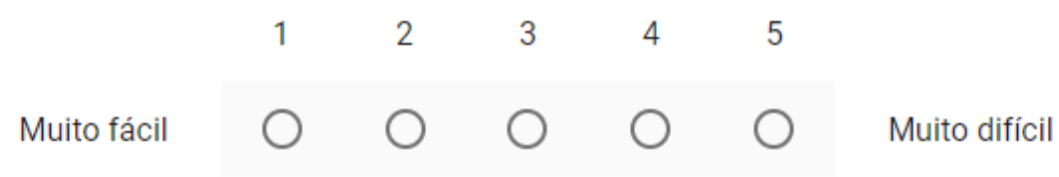

Figure 6.1: Likert scale used

\subsection{Results}

\subsubsection{Expert evaluation}

The session took place in the meeting room at OPT headquarters. Two of the company's experts on usability and design application development were present in this session.

The general conclusion was that the interfaces were very intuitive and easy to interact with. In other words, the usability test was positive. The experts also highlighted a very important detail: the users want information fast. However, the design to check schedules demands too many button clicks. To solve this, they mentioned that bus and subway stops near the user location should be added in the main page map. This way, the user could press the desired stop and instantly see the lines passing there, and with a second click they would be able to check the schedules. It was 
explained to the experts that this work is supposed to deliver guidelines to future route planner developments, creating a framework that the developers can work with.

The overall design was considered appealing and coherent. These suggestions are presented in the next sections.

\subsubsection{Bus interfaces}

The suggestions of the experts towards the bus interfaces were as followed:

- Search feature - A search feature would be a valuable asset to implement in the operator and stops bus interface, namely Figure 5.7 (in both interfaces). Considering the fact that some bus lines (i.e. STCP 301) have a large quantity of stops, the scrolling on the screen would be bothersome. The search feature would allow the user to quickly search for the desired stop.

- Separation of the bus stops - The overall design of the interface in Figure 5.9 (a) does not take into consideration what is reality. Bus stops from each side of the street are different, and in the example they are treated as equal. What this means is that bus stops from each side of the road are two separate stops. That should be considered in a further iteration of the design.

- Focus on the bus stop - In the design, there should be a focus on the bus stop instead of on the line. A stop is composed of many lines, so the information provided could automatically indicate all the lines when someone presses a stop, instead of having to click various buttons to reach a certain stop. This could be easily solved by adding the nearest stops on the map in the main page, which would allow the user to press it and gain information about which lines pass there.

- Accessibility stops - A feature to only show stops/stations with accessibility should be implemented. Eventually a customization feature could be created and so the user would be all to pick, for instance, if he/she wants to walk or not, or change transport vehicles or not. This could be implemented in the definitions in the interface menu.

- Anomalies in bus lines - In Figure 5.7 (b) the user cannot see any anomalies or problems with each line, as exemplified in Figure 5.5.This could eventually be implemented easily since the app should has the current localization of the user in consideration. For that reason, it would only show the nearby lines anomalies. Delays should by no means be covered since there is a chance of $90 \%$ for a bus to be delayed 2 minutes.

\subsubsection{Subway interfaces}

The suggestions of the experts towards the subway interfaces were as followed: 
- Travel time in stations - An addition of information related to the travel time since the entrance of a subway station until the actual vehicle is very important for mobility reduced people. Therefore, this should be implemented in future design iterations, most likely in Figure 5.5 (b).

- Setting the overcrowd/low crowd icon next to each departure - Since there are usually two directions in each stop/station, these icons should indicate which direction is or is not overcrowded. In the overall design that was developed, for instance is Figure 5.6 (a), the information regards both stops as one, while in truth, there are two stops, one in each direction.

\subsubsection{Route planner interfaces}

The suggestions of the experts towards the route planner interfaces were as followed:

- Replacing buttons - Removing the buttons at the bottom right corner in Figure 5.10 (a) and replacing them with just an arrow pointing to the right or simply a swipe right on the screen was mentioned. Alternatively, the map could disappear and this interface would represent a mini survey with, for instance, a five level difficulty bars so the user could express how easy it is for him/her to walk and change transport vehicles. The next interface would then have the answer into consideration, and the app would create routes that go into accord with what the user answered.

- Waiting time - Eventually having the waiting time for each vehicle in Figure 5.10 (b) would be a good asset.

- Itinerary connection In Figure 5.11 (a), there should be a button that would direct the user to the other part of the itinerary. The current design takes into account the users positioning and location to advance to the next itinerary. Nevertheless, a manual feature is needed. Something as simple as an arrow pointing to the right would be ideal.

The general consensus regarding the information provided to the users, specially to mobility reduced ones, was that it is well handled and extremely accurate. The experts could not imagine any other information that could potentially be useful for that group in specific. This means that the requirements once acquired in chapter 4 were consistent, and therefore the work developed met its purpose.

\subsubsection{Inquiry}

The inquiry counted with around 30 people from various ages. In Figure 6.2 we can see the different age ranges of the participants. The amount of people who participated was very satisfying, considering that many of them were 50 years old or over. It is worth noting that close to a third of the participants had physical, sensory or cognitive limitations. 


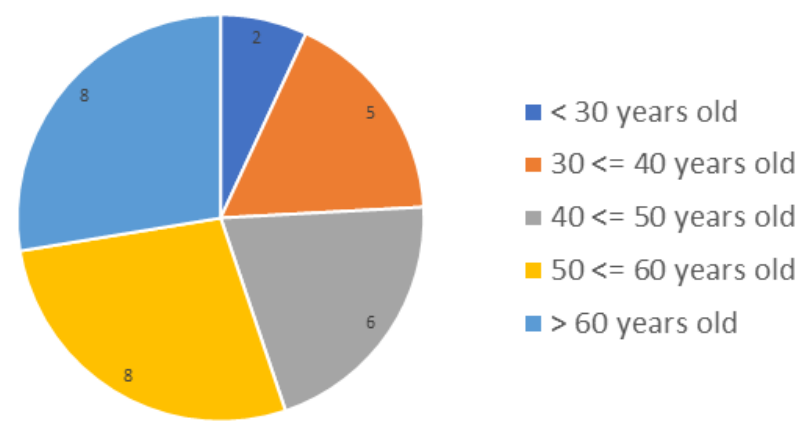

Figure 6.2: Age ranges of people who participated in the inquiry for the usability evaluation

Each interface average scores can be seen in Table 6.1. Overall, most people considered the design appealing and intuitive. Only the interfaces with a bigger amount of information had a score of 2 or higher (i.e. easy, medium, difficult or very difficult). Some users also mentioned that the information was very helpful to mobility reduced people. The inquiry had an open question after each interface, but barely anyone wrote any comments besides the good choice in colors and clean design. However, two people mentioned that the map in the main interface should contain the nearby stops, which goes with what the experts said.

The fact that most scores are around 1 and 2 is extremely important in this work, as it has the objective to create simple and intuitive mock-up interfaces that contained a substantial amount of information towards mobility reduced people and people in general. Despite this, there were a handful of people who considered several interfaces confusing, especially the route planning and the subway ones, namely Figure 5.6 (a) and Figure 5.12 (a). Information is important, but so is the way one shares it, and these interfaces might be able to reach most people, but there will always be a small group who will find them confusing.

\begin{tabular}{llc}
\hline & \multicolumn{2}{l}{ Average score } \\
\hline Interface & (a) & (b) \\
\hline Figure 5.1 & 2.0 & - \\
\hline Figure 5.5 & 1.1 & 1.1 \\
\hline Figure 5.6 & 1.8 & 1.7 \\
\hline Figure 5.7 & 1.9 & 1.2 \\
\hline Figure 5.8 & 1.4 & 2.0 \\
\hline Figure 5.10 & 2.0 & 2.1 \\
\hline Figure 5.11 & 2.4 & - \\
\hline Figure 5.12 & 2.5 & - \\
\hline
\end{tabular}

Table 6.1: Interface average scores obtained from the usability inquiry.

a The numbers 1 and 5 represent very easy and very difficult, respectively.

${ }^{b}$ The (a) and (b) represent the interfaces at the right and at the left of each figure, respectively. 


\section{Chapter 7}

\section{Conclusions and future work}

\subsection{Conclusions}

In this thesis a user-centered design was followed to define a set of guidelines to design route planners of public transport for socially excluded groups. To achieve this goal, a three-step methodology was defined: (i) Requirements elicitation; (ii) Interfaces development; (iii) and Usability evaluation. In the first phase, a literature review and data collected in the field, through interviews and a survey, in a medium-sized European Metropolitan Area, was conducted. This allowed to identify the main social excluded groups, its main limitations and needs, and the information that is lacking in route planners of public transport was also identified. Based on the information collected, a set of requirements to design the user interfaces were defined. Then, the mock-ups were designed following these requirements. Lastly, the usability evaluation was accomplished by promoting a session with experts in application development for public transports and by conducting a survey to the population. In this process, the difculty in perceiving the information was evaluated.

The social excluded group selected to study in this work were the elderly. This group was selected based on four main criteria: (i) The elderly population is growing at a fast rate, (ii) The elderly usually have physical, sensitive and/or cognitive limitations that limit their perception and their mobility when physical obstructions as steps or edges are present on the path; (iii) With age, the elderly may acquire more than one of those limitations; and (iv) The elderly have particular needs of mobility, sometimes limited by their inability to drive. The results achieved demonstrate that the methodology defined in this work was coherent and robust. The overall results demonstrate that the information provided to the users, especially to mobility reduce ones, was well handled and extremely accurate. Most people considered the design appealing and intuitive. This work covered most of the information needed to improve elderly people public transports usage experience.

During the various research phases, including literature review, user observation, usability tests and interviews with experts, a number of usage patterns, themes and recommendations started to arise. The compilation of these findings resulted in a set of guidelines for designing mobile applications that may be used as guidelines for software developers and policymakers to support information exchange in public transport. Such guidelines can be described as follows: 
(i) Incentivise user participation: user participation is crucial in developing interfaces both for the requirements elicitation as for the usability evaluation phase. Without the interviews and the survey conducted, the requirements specifications would only be dictated by the literature review, and there is a need to know people's opinions and compare them to the bibliography. For the usability evaluation, the best way to improve the design and identify what information is lacking is to promote feedback within the users. This will help future iterations to be more successful.

(ii) Weight the data: a wide variety of information can be initially thought and discussed, but it is essential to keep in mind what information are the users most interested in. This means that it is important to not overboard the interfaces with unnecessary data.

(iii) Ensure an intuitive design: despite the age range that an app is oriented to, it should always be intuitive to provide high usability. Information must be clear and the icons should be carefully chosen.

This work covered most of the information needed to improve public transports usage experience of mobility reduced people, so the principal intent of this work was successfully reached and the results were highly satisfactory. If the project blooms into a real route planning application, it will be a big motivation to continue working around this subject.

An article about this thesis was submitted to the 3rd EAI International Conference on Intelligent Transport Systems (http://futuretransport.org/call-for-papers/). This conference is part of the 5th annual Smart City 360Summit, promoting multidisciplinary scientific collaboration to solve complex societal, technological and economic problems of emerging Smart Cities. The conference focuses on three main purposes:

- To enable researchers in ITS to share their achievements and findings in different areas of Intelligent Transport Systems and logistics;

- To bring together the relevant ITS stakeholders and to address several questions as: what role has research and end users in the development of ITS solutions? How can the industry maximize the use of research outcomes? Can there be intelligent logistics operations in city distribution process?;

- Raise collaboration among different research fields such as: logistics and operations management; Architecture and Urbanism.

Various topics will be addressed in this conference. The article will be included in "travel and traffic information" topic. It is worth noting that the paper, if accepted, will be submitted for publication by Springer and made available through SpringerLink Digital Library.

The biggest markets are more lucrative and, for now, it is understandable that companies focus their investment towards them. However, later on, the elderly will be a major influence in the biggest markets, so it can be concluded that this work has an enormous potential to create a positive impact in the future. Nevertheless, as technology grows, so does the development infrastructures; these are able to offer new and improved commodities to mobility reduced groups that are yet to be seen, and when this happens this work will require a full review. 


\subsection{Future work}

Even though this work met its goal by structuring information regarding socially excluded people that no other journey planner currently provides, there is still a considerable amount of tasks that need to be accomplished before it is completely finished.

One of those tasks is the creation of a better overall design for the interfaces, as no professional designer was present in the development. Another task that is worth mentioning is the development of underground subway station maps in order to pinpoint the exact location of all main infrastructures such as elevators, automatic staircases and bathrooms to provide an even better amount of information, although this task seems quite difficult to complete since subway footprints might be private. 


\section{References}

ISO 9241-11. INTERNATIONAL STANDARD Usability : Definitions and concepts. 2018, 2018.

Marco André Moreira Amador. Journata - Designing the interface of a mobile application for exchanging public transport information among travellers. 2014.

Kate Barber, Rob Sheldon, Alex Phillips, Hui Lu, Peter Burge, Chris Heywood, and Peter Lee. The impact of real-time information on passengers' value of bus waiting time. Transportation Research Procedia, 31(2016):18-34, 2018. ISSN 23521465. doi: 10.1016/j.trpro.2018.09.043. URL https://doi.org/10.1016/j.trpro.2018.09.043.

Kristóf Bérczi, Alpár Jüttner, Marco Laumanns, and Jácint Szabó. Arrival time dependent routing policies in public transport. Discrete Applied Mathematics, 251:93-102, 2018. ISSN 0166218X. doi: 10.1016/j.dam.2018.05.031. URL https://doi.org/10.1016/j.dam. 2018.05 .031$.

Tania Burchardt, Julian Le Grand, and David Piachaud. Social exclusion in britain 1991-1995. Social Policy \& Administration, 33(3):227-244, 1999. doi: 10.1111/1467-9515.00148. URL https://onlinelibrary.wiley.com/doi/abs/10.1111/1467-9515.00148.

Noel Cass, Elizabeth Shove, and John Urry. Social exclusion, mobility and access. The Sociological Review, 53(3):539-555, 2005. doi: 10.1111/j.1467-954X.2005.00565.x. URL https://doi.org/10.1111/j.1467-954X.2005.00565.x.

A Church, M Frost, and K Sullivan. Transport and social exclusion in london. Transport Policy, 7(3):195 - 205, 2000. ISSN 0967-070X. doi: https://doi.org/10. 1016/S0967-070X(00)00024-X. URL http://www.sciencedirect.com/science/ article/pii/s0967070X0000024X.

Council. Joint report by the commission and the council on social inclusion. 2004. URL http://ec.europa.eu/employment_social/soc-prot/soc-incl/final_ joint_inclusion_report_2003_en.pdf.

Mark A. P. Davies. Perceived information quality. Journal of International Consumer Marketing, 13(4):29-50, 2001. doi: 10.1300/J046v13n04__03. URL https://doi.org/10.1300/ J046v13n04_03.

Jeremy Barron Efraim Jaul. Age-related diseases and clinical and public health implications for the 85years old and over population, 2017. URL https://www.ncbi.nlm.nih.gov/pmc/ articles/PMC5732407/.

European Comission. Poverty and social exclusion. 2010. URL http://ec.europa.eu/ commfrontoffice/publicopinion/archives/ebs/ebs_355_en.pdf. 
EUROSTAT. People at risk of poverty or social exclusion, by age group. 2017. URL https://ec.europa.eu/eurostat/statistics-explained/index. php/People_at_risk_of_poverty_or_social_exclusion\#Analysis_of_ populations_at_risk.

Lindsay Evett and David Brown. Text formats and web design for visually impaired and dyslexic readers - Clear Text for All. Interacting with Computers, 17(4):453-472, 2005. ISSN 09535438. doi: 10.1016/j.intcom.2005.04.001.

João Falcão and Teresa Galvão. Service Orientation in Holonic and Multi Agent Manufacturing and Robotics. 472:225-234, 2013. doi: 10.1007/978-3-642-35852-4. URL http://link. springer.com/10.1007/978-3-642-35852-4.

Marta Campos Ferreira, Tânia Fontesz, Vera Costa, Teresa Galvão Dias, José Luís Borges, and João Falcão E Cunha. Evaluation of an integrated mobile payment, route planner and social network solution for public transport. Transportation Research Procedia, 24:189-196, 2017. ISSN 23521465. doi: 10.1016/j.trpro.2017.05.107.

Robert Follmer, Barbara Lenz, Birgit Jesske, and Sylvia Quandt. Ergebnisbericht - Mobilität in Deutschland 2008. Tempo, page 214, 2008. doi: http://www.mobilitaet-in-deutschland.de/pdf/ MiD2008_Tabellenband.pdf.

Freire de Sousa Jorge Pinho de Sousa Fontes, Tânia, Teresa Galvão, and José Correia. A MultiUser Integrated Platform for Supporting the Design and Management of Urban Mobility Systems. Transportation Research Procedia, 27(September):35-42, 2018. ISSN 23521465. doi: 10.1016/j.trpro.2017.12.158.

Johan Holmgren. Meta-analysis of public transport demand. Transportation Research Part A: Policy and Practice, 41(10):1021 - 1035, 2007. ISSN 0965-8564. doi: https://doi.org/10.1016/ j.tra.2007.06.003. URL http://www.sciencedirect.com/science/article/pii/ s096585640700047X.

J Houghton, J Reiners, and C Lim. Intelligent transport: How cities can improve mobility. IBM Institute for Business Value, pages 1-6, 2009. URL http://scholar.google.com/scholar?hl=en $\{\&\}$ btnG=Search $\{\&\}$ q=intitle:

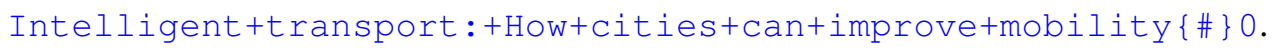

N. B. Hounsell, B. P. Shrestha, M. McDonald, and A. Wong. Open Data and the Needs of Older People for Public Transport Information. Transportation Research Procedia, 14(0):4334-4343, 2016. ISSN 23521465. doi: 10.1016/j.trpro.2016.05.355. URL http://dx. doi .org/10. $1016 / j . t r p r o .2016 .05 .355$.

infas \& DLR. Mobilität in Deutschland (MID) 2008. Bundesministerium für Verkehr Bau und Stadtentwicklung, 2008(July 2007), 2008.

Md. Kamruzzaman, Tan Yigitcanlar, Jay Yang, and Mohd Afzan Mohamed. Measures of transport-related social exclusion: A critical review of the literature. Sustainability, 8(7):Artical number-696, July 2016. doi: 10.3390/su8070696. URL https: / / eprints . qut . edu . au/ $97604 /$.

Susan Kenyon, Glenn Lyons, and Jackie Rafferty. Transport and social exclusion: Investigating the possibility of promoting inclusion through virtual mobility. Journal of Transport Geography, 10(3):207-219, 2002. ISSN 09666923. doi: 10.1016/S0966-6923(02)00012-1. 
Bracey Kezz. What is figma?, 2018. URL https://webdesign.tutsplus.com/ articles/what-is-figma--cms-32272.

Manuela Lodovici and Nicoletta Torchio. Social exclusion in eu transport. 2015. URL http: //www. docutren.com/pdf/boletin/ [IIIA 201440] .pdf.

Karen Lucas. Transport and social exclusion: Where are we now? Transport Policy, 20:105-113, 2012. ISSN 0967070X. doi: 10.1016/j.tranpol.2012.01.013. URL http://dx.doi.org/ $10.1016 / j . t r a n p o l .2012 .01 .013$.

Karen Lucas, Giulio Mattioli, Ersilia Verlinghieri, and Alvaro Guzman. Transport poverty and its adverse social consequences. Proceedings of the Institution of Civil Engineers - Transport, 169(6):353-365, 2016. doi: 10.1680/jtran.15.00073. URL https://doi.org/10.1680/ jtran.15.00073.

R L Mackett. Overcoming the barriers to access for older people. (November):1, 2014. URL http://www.ageactionalliance.org/wordpress/wp-content/uploads/ 2014/11/Overcoming-the-barriers-to-access-Nov-14.pdf.

Roger L. Mackett and Roselle Thoreau. Transport, social exclusion and health. Journal of Transport and Health, 2(4):610-617, 2015. ISSN 22141405. doi: 10.1016/j.jth.2015.07.006.

Manchester School of Architecture. Analysis of Journey Planner Apps and Best Practice Features. (October), 2016.

J. Nielsen and R. Budui. Mobile usability, 2012. URL http://ptgmedia.pearsoncmg . com/images/9780321884480/samplepages/0321884485.pdf.

Jakob Nielsen. Usability 101: Introduction to usability, 2012. URL https://www . nngroup. com/articles/usability-101-introduction-to-usability/.

Lauren Redman, Margareta Friman, Tommy Gärling, and Terry Hartig. Quality attributes of public transport that attract car users: A research review. Transport Policy, 25:119-127, 2013. ISSN 0967070X. doi: 10.1016/j.tranpol.2012.11.005.

Dillip Rout, Nilesh Borole, P. Vedagiri, Tom V. Mathew, and Nidhi Goel. Multimodal Public Transit Trip Planner with Real-time Transit Data. Procedia - Social and Behavioral Sciences, 104:775-784, 2013. ISSN 18770428. doi: 10.1016/j.sbspro.2013.11.172. URL http: / / dx. doi.org/10.1016/j.sbspro.2013.11.172.

Susumu SAITO and Katsuhiko OGAWA. Ergonomics of human-system interaction. The Japanese journal of ergonomics, 30(1):1-1, 2011. ISSN 0549-4974. doi: 10.5100/jje.30.1.

J. Schlingensiepen, E. Naroska, T. Bolten, O. Christen, S. Schmitz, and C. Ressel. Empowering People with Disabilities Using Urban Public Transport. Procedia Manufacturing, 3(January 1980):2349-2356, 2015. ISSN 23519789. doi: 10.1016/j.promfg.2015.07.382. URL http: //dx.doi.org/10.1016/j.promfg.2015.07.382.

Tim Schwanen, Karen Lucas, Nihan Akyelken, Diego Cisternas Solsona, Juan Antonio Carrasco, and Tijs Neutens. Rethinking the links between social exclusion and transport disadvantage through the lens of social capital. Transportation Research Part A: Policy and Practice, 74: 123-135, 2015. ISSN 09658564. doi: 10.1016/j.tra.2015.02.012. URL http://dx.doi. org/10.1016/j.tra.2015.02.012. 
Sally Shortall. Are rural development programmes socially inclusive? social inclusion, civic engagement, participation, and social capital: Exploring the differences. Journal of Rural Studies, 24(4):450 - 457, 2008. ISSN 0743-0167. doi: https://doi.org/10.1016/j. jrurstud.2008.01.001. URL http://www.sciencedirect.com/science/article/ pii/s0743016708000089.

Seyed Hassan Khalifeh Soltani, Mashita Sham, Mohamad Awang, and Rostam Yaman. Accessibility for Disabled in Public Transportation Terminal. Procedia - Social and Behavioral Sciences, 35(December 2011):89-96, 2012. ISSN 18770428. doi: 10.1016/j.sbspro.2012.02.066. URL http://dx.doi.org/10.1016/j.sbspro.2012.02.066.

TIP. Relatório e contas, 2015. URL https : / /www . linhandante.com/uploadFiles/RC_ TIP_2015-20160329.pdf.

David Travis. Iso 13407 is dead. long live iso 9241-210!, 2011. URL https://www. userfocus.co.uk/articles/iso-13407-is-dead.html.

UK Social Exclusion Unit. Making the connections: Final report on transport and social exclusion. 2003. URL https://www.ilo.org/wcmsp5/groups/public/---ed_emp/ ---emp_policy/---invest/documents/publication/wcms_asist_8210.pdf.

Population Division Department of Economic United Nations and Social Affairs. World Aging Population 2017. Number Highlights. 2017. ISBN 9789210510929. doi: 10.1049/el:20000788.

Donggen Wang and Shenjing He. Mobility, sociability and well-being of urban living. Mobility, Sociability and Well-Being of Urban Living, pages 1-282, 2015. doi: 10.1007/ 978-3-662-48184-4.

Patrick Ştefănescu, Marian Mocan, Werner Ştefănescu, and Petrişor Viorel Neculai. Trip Planners Used in Public Transportation. Case Study on the City of Timişoara. Procedia - Social and Behavioral Sciences, 124:142-148, 2014. ISSN 18770428. doi: 10.1016/j.sbspro.2014.02.470. 